\title{
MODELAGEM DA CAMADA LIMITE NOTURNA (CLN) DURANTE A ÉPOCA ÚMIDA NA AMAZÔNIA, SOB DIFERENTES CONDIÇÕES DE DESENVOLVIMENTO
}

\author{
ROSA MARIA N. SANTOS ${ }^{1}$, GILBERTO FISCH${ }^{2}$, A. J. DOLMAN ${ }^{3}$, MARTEEN WATERLOO ${ }^{3}$ \\ 1* Instituto Nacional de Pesquisas Espaciais (INPE), \\ Centro de Previsão de Tempo e Estudos Climáticos (CPTEC). \\ São José dos Campos - SP. E-mail: rosa_sto@yahoo.com \\ ${ }^{2}$ Centro Técnico Aeroespacial(CTA/IAE-ACA) \\ São José dos Campos, SP, E-mail: gfisch@cta.iae.br \\ ${ }^{3}$ Vrije Universiteit (VU) \\ Amsterdam - Amsterdã, Holanda \\ Recebido Julho 2006 - Aceito Maio 2007
}

\begin{abstract}
RESUMO
Um estudo de modelagem utilizando o modelo unidimensional OSU-CAPS foi realizado com o intuito de investigar o desenvolvimento da Camada Limite Noturna (CLN), durante a época úmida na região Amazônica, visando aumentar os conhecimentos sobre seu funcionamento sob diferentes condições ambientais. O Modelo simulou a profundidade $\left(\mathrm{h}_{\mathrm{i}}\right)$ e a estrutura da CLN sobre 3 sítios experimentais (RM, Floresta e FNS) em Rondônia - RO, oeste da região Amazônica e estas simulações foram comparadas com observações locais . Verificou-se que o modelo consegue representar a estrutura e o desenvolvimento da CLN, sobre os 3 sítios As simulações mostraram que RM (transição floresta-pastagem) e a Floresta apresentaram características similares de desenvolvimento da CLN, principalmente no período entre $19 \mathrm{hl}$ e 06hl. Para a FNS (área totalmente desmatada) as análises indicaram que a CLN tem um desenvolvimento parecido com aquele observado sobre áreas urbanas - onde uma camada de mistura turbulenta rasa é observada próximo à superfície, nas primeiras horas da noite.
\end{abstract}

Palavras-chave: modelagem matemática, Modelo OSU-CAPS, balão cativo

\begin{abstract}
MODELLING THE NOCTURNAL BOUNDARY LAYER (NBL) DURING THE WET SEASON IN THE AMAZONIA UNDER DIFFERENT DEVELOPMENT CONDITIONS.

A modelling study using the OSU-CAPS model has been carried out in order to investigate the Nocturnal Boundary Layer (NBL) evolution during the wet season over the Amazon region to increase the existing knowledge about its dynamics under different environmental conditions. The model simulated the NBL depth $\left(\mathrm{h}_{\mathrm{i}}\right)$ and structure over 3 experimantal sites (RM, Forest and FNS) in Rondônia-RO, western Amazonian region, and these simulations have been compared to the observational. It was verified that the model has reasonably represented the NBL structure and evolution to the 3 sites. Simulations showed that RM (transiction forest-pasture) and the Forest sites have presented similar NBL development characteristics mainly for the period between $7 \mathrm{pm}$ and $06 \mathrm{am}$. In the case of FNS (pasture) the analyses pointed out the NBL development to be similar to the one observed in urban areas - where a shalow mixing layer migth be watched close to the surface, in the evening.
\end{abstract}

Keywords: numeric modelling, OSU-CAPS model, tethraed balloon

* Filiação e Endereço atuais: Instituto Nacional de Pesquisas da Amazônia (INPA)/Programa LBA Av. André Araújo, 2936, Campus II - Aleixo, CEP 69060-001, Manaus - AM, Fone: +55 92 3643-3620 


\section{INTRODUÇÃO}

A Camada Limite Estável Noturna (CLN) sobre o continente, ocorre em resposta ao resfriamento da superfície devido à emissão de radiação de onda longa para o espaço, sendo caracterizada pela presença de uma camada de inversão térmica próxima à superfície. Os processos atmosféricos possuem uma escala de tempo da ordem de algumas horas, com extensão vertical máxima em torno de 500 m (Stull, 1988; Holtslag e Duynkerke, 1998). É, geralmente, definida como sendo uma camada de turbulência intermitente, o número de Richardson gradiente é subcrítico - aproximadamente entre $0 \mathrm{e}$ 0,25 e acima da qual o cisalhamento do vento e o fluxo de calor são pequenos (Garrat, 1992). Na CLN o empuxo negativo age para suprimir a turbulência, diminuindo sua profundidade; além disso, movimentos atmosféricos (tais como ondas de gravidade) podem coexistir com a turbulência, tornando sua estrutura mais complexa e; finalmente, há o papel preponderante dos efeitos radiativos (emissão de ondas longas) no desenvolvimento de uma camada de inversão, que pode existir em condições de calmaria e, portanto, na ausência de turbulência (Stull, 1988; Mahrt, 1998; Mahrt et al., 1999).

Tal complexidade dificulta a descrição e modelagem dos parâmetros que definem sua estrutura. Devido a isto, um grande número de questões à cerca do desenvolvimento da CLN ainda permanece sem resposta, sendo, por conseqüência, ainda pouco explorada no desenvolvimento da modelagem de meso e de grande escala (Nappo e Johansson, 1998). Há, portanto, a necessidade de solucionar problemas encontrados por modelos numéricos que tentam capturar fenômenos atmosféricos que ocorrem sob uma escala de dezenas de metros a algumas centenas de quilômetros, durante as condições estavelmente estratificadas noturnas (McNider et al., 1995; Poulos e Bossert, 1995; Poulos et al., 2002), sobretudo em regiões como a Amazônia - onde biosfera e atmosfera interagem de forma tão intensa e complexa.

Diversos estudos (a maioria deles observacionais e conduzidos para regiões de médias e altas latitudes) têm sido conduzidos a fim de investigar diferentes aspectos do desenvolvimento da CLN. Alguns destes estudos classificaram a CLN em duas categorias, de acordo com a estratificação da turbulência, a saber: camada limite muito estável e camada limite fracamente estável (Malhi, 1995; Oyha, et al., 1997; Mahrt, 1998). Outros estudos, por outro lado, identificaram características especiais em regimes muito estáveis ou intermitentes (Holtslag e Nieuwstadt, 1986; Smedman, 1988; Derbyshire, 1990).

Sun et al. (2004) mostraram que instabilidades térmicas e mecânicas, causadas pela propagação horizontal e vertical de ondas solitárias e de gravidade, funcionam como um mecanismo que inicia eventos de mistura turbulenta - turbulência intermitente
- dentro da CLN. Além disso, episódios de turbulência intermitente também estão associados à mudanças na pressão atmosférica e na direção do vento próximo à superfície.

Sob condições de estabilidade fraca, a turbulência costuma ser contínua e profunda e a CLN possui um topo bem definido, como determinaram diversos estudos observacionais e de laboratório (Lenschow et al., 1988; Van Ulden e Wieringa, 1996; Ohya et al., 1997) e de modelagem (Derbyshire, 1990; Zilitinkevich e Mironov, 1996). Já no caso de forte estabilidade, a turbulência é fraca e/ou intermitente, mesmo próximo à superfície, sendo estratificada em camadas e podendo, algumas vezes, ser mais forte no topo da inversão de superfície (Mahrt, 1985; Ohya et al., 1997), onde é por vezes gerada pelo cisalhamento mecânico abaixo do pico de vento (Smedman, 1988). Alguns estudos também caracterizam a intermitência dentro de camadas fortemente estáveis em termos da relação entre o fluxo total do período amostrado e a ocorrência de maior atividade turbulenta dentro desse período (Howell e Sun, 1999; Coulter e Doran, 2002; Doran, 2004).

O comportamento da CLA sobre a região amazônica tem sido mais estudado durante o período diurno e, de modo geral, o desenvolvimento da CLA é maior sobre áreas de pastagem (mais secas e quentes) que em áreas de floresta (onde temperaturas e umidade se mantêm, relativamente, constante) durante a estação seca; durante a estação úmida, no entanto, floresta e pastagem apresentam um desenvolvimento da CLA bem similar, com temperaturas e umidade, praticamente iguais (Fisch et al., 2004).

Santos (2005) observou também que à noite, durante a estação úmida, a pastagem apresenta períodos de maior umidade que a floresta, o que pode estar relacionado ao aumento do escoamento superficial ("runoff") sobre áreas de pastagem, devido ao efeito da compactação do solo.

Neste trabalho, avaliou-se o desenvolvimento da CLN, durante a época úmida na região da Amazônia, a partir de simulações realizadas por um modelo numérico, com o objetivo de investigar algumas situações observadas em campo, visando deste modo aumentar os conhecimentos sobre seu funcionamento devido a diferentes condições iniciais e/ou de contorno e forçantes externas, tais como: a ocorrência de precipitação e as condições de umidade do solo; desmatamento (diferenças e/ou semelhanças entre áreas de pastagem, transição florestapastagem e floresta).

\section{MATERIAL E MÉTODOS}

\subsection{Dados e Área Experimental}

A área de abrangência desse estudo está localizada na região oeste da Amazônia Legal, no Estado de Rondônia - RO e compreendeu três sítios de medidas: Reserva Biológica do 
Rio Jaru - Floresta $\left(10^{\circ} 08^{\prime} 26^{\prime \prime} \mathrm{S}, 61^{\circ} 54^{\prime} 28^{\prime \prime} \mathrm{W}\right.$ e $\left.120 \mathrm{~m}\right)$; Rolim de Moura - RM, representativo de uma área de transição floresta-pastagem ( $\left(11^{\circ} 42^{\prime} 17^{\prime \prime}\right.$ S, 61 6 46' 38” W e 225 m); e a pastagem - Fazenda Nossa Senhora Aparecida (FNS), no município de Ouro Preto d'Oeste ( $10^{\circ} 46^{\prime} 25^{\prime \prime} \mathrm{S}, 62^{\circ} 20^{\prime} 13^{\prime \prime} \mathrm{W}$ e $293 \mathrm{~m}$ ). Os dados utilizados no trabalho foram coletados nestes sítios durante a Campanha de Mesoescala Atmosférica da Estação Úmida ("Wet Season Atmospheric Mesoscale Campaign") do experimento LBA - WetAMC-LBA, realizada entre janeiro e fevereiro de 1999 (ver Silva Dias et al., 2002).

Para inicializar o modelo utilizado, foram utilizados perfis verticais da temperatura do ar $\left(\mathrm{em}^{\circ} \mathrm{C}\right)$, umidade específica (em g.kg $\left.{ }^{-1}\right)$ e vento $\left(\mathrm{em} \mathrm{m} \cdot \mathrm{s}^{-1}\right)$ - componentes u, v e $\mathrm{w}$ (cujos valores foram calculados a partir da equação da divergência do vento para a área de abrangência das radiossondagens), obtidos a partir de balão cativo e radiossondagem; bem como os parâmetros e condições iniciais à superfície para cada sítio experimental (TABELA 1), tais como comprimento de rugosidade para o momento e para o calor $\left(\mathrm{Z}_{0}\right.$ e $\mathrm{Z}_{0 \mathrm{H}}$, respectivamente, em $\mathrm{m}$ ), albedo da superfície ( $\alpha$, adimensional), tipo de solo e temperatura do solo (em K) para 2 camadas definidas no modelo e a temperatura de referência (em K) do ar próximo à superfície (usada no cálculo inicial do balanço de radiação).

Tabela 1 - Parâmetros iniciais do modelo para a Floresta, FNS e $\mathrm{RM}$

\begin{tabular}{|c|c|c|c|}
\hline & Floresta & FNS & $\mathbf{R M}$ \\
\hline $\mathrm{Z}_{0}(\mathrm{~m}) * *$ & 3,03 & 0,06 & 0,053 \\
\hline $\mathrm{Z}_{0 \mathrm{H}}(\mathrm{m}) * * *$ & 0,303 & 0,006 & 0,0053 \\
\hline Albedo ** & 0,123 & 0,171 & 0,171 \\
\hline $\mathrm{T}_{\mathrm{ref}}(\mathrm{K})^{*+}$ & 300,65 & 300,65 & 300,65 \\
\hline $\mathrm{T}_{\text {SOLO1 }}(\mathrm{K})(5 \mathrm{~cm}) *$ & 298,0 & 300,0 & 299,0 \\
\hline $\mathrm{T}_{\mathrm{SOLO} 2}(\mathrm{~K})(1 \mathrm{~m}) *$ & 298,0 & 300,0 & 299,0 \\
\hline
\end{tabular}

Fontes: * Souza et al. (1996); ** Wright et al. (1996); *** $\mathrm{Z}_{\mathrm{OH}}=0,1 \mathrm{Z}_{0}$ (Garratt, 1992); ${ }^{*+}$ Estimado a partir da média observada da temperatura do ar à superfície.

Medidas de temperatura do solo obtidas na Floresta e na FNS, realizadas por Alvalá et al. (2002) em três diferentes profundidades - 10, 20 e $40 \mathrm{~cm}$ - mostraram que a variação térmica nas primeiras camadas do solo é pequena. Assim sendo, no presente trabalho considerou-se para a inicialização do modelo as temperaturas de solo, a 0,05 e $1 \mathrm{~m}$, calculadas através da interpolação dos valores apresentados por Souza et al. (1996), para os sítios de floresta e de pastagem, em Marabá - PA, sítios estes que apresentam solos com características aproximadamente semelhantes àquelas encontradas nos sítios de Rondônia.

\subsection{Características do Modelo}

Para realizar as simulações neste estudo foi escolhido o Modelo Acoplado da Camada Limite-Planta-Solo - OSU-CAPS ("Oregon State University - Coupled Boundary Layer-Plant-Soil Model"), por ser o esquema de superfície atualmente acoplado a uma das versões do modelo de meso-escala ETA, implementado operacionalmente no CPTEC/INPE. O OSU-CAPS é um esquema unidimensional (modelo de coluna) desenvolvido para simular a mistura turbulenta na Camada Limite, considerando as condições do solo e da superfície vegetada, para aplicações nas quais não seja possível uma alta resolução vertical na descrição da (caso dos MCGs). Alguns dos principais processos de mistura da são descritos neste modelo, tais como o balanço de energia à superfície, a mistura turbulenta, o entranhamento no topo da camada e a estabilidade atmosférica.

Nesta versão do OSU-CAPS, o modelo elaborado por Troen e Mahrt (1986) para descrever a Camada Limite Planetária foi acoplado ao modelo ativo de duas camadas de solo de Mahrt e Pan (1984), incorporando também a formulação desenvolvida por Mahrt e Ek (1984) para a evapotranspiração de Penman e o modelo do dossel de Pan e Mahrt (1987). Esta composição do modelo é suficientemente robusta para aproximar, de modo satisfatório, os processos físicos considerados como os mais importantes, porém simples o suficiente para permitir que simulações de baixa e alta resolução sejam executadas em poucos minutos por um computador pessoal, tanto para condições diurnas (instáveis) como para noturnas (estáveis).

A altura do topo da camada, ou profundidade da CLN no modelo - $h$, é determinada por uma equação diagnóstica, tal que,

$$
\mathrm{h}=\mathrm{Ri}_{\mathrm{CR}} \frac{{ }_{0}|\mathbf{V}(\mathrm{h})|^{2}}{\mathrm{~g}\left(,(\mathrm{~h})-,{ }_{0}\right)} .
$$

Sendo $\theta_{\mathrm{o}}$ a temperatura potencial (em K) no primeiro nível do modelo acima da superfície, $\operatorname{Ri}_{\mathrm{CR}}(=0,25)$ o número de Richardson crítico da camada, $\theta$ (h) a temperatura potencial no topo da camada e $\mathbf{V}(\mathrm{h})$ a velocidade horizontal do vento no topo da camada. Esta aproximação para $h$ requer a especificação de uma "temperatura potencial nos baixos níveis, $\theta_{0}^{*}$, definida da seguinte forma:

$$
\theta_{0}^{*}=\left\{\begin{array}{ll}
\theta_{0} & \text {, caso EstAvel } \\
\theta_{0}+\mathrm{C} \frac{\overline{\left(\mathrm{w}^{\prime} \theta^{\prime}\right)_{\mathrm{S}}}}{\mathrm{w}_{\mathrm{S}}} & \text {, caso InstAvel }
\end{array}\right\} ;
$$

sendo $\overline{\left(w^{\prime} \theta\right)_{\mathrm{s}}}$ o fluxo de calor médio à superfície.

Ainda no cálculo da altura da CLA, o modelo original considera, inicialmente, a altura $h_{i}$ como o valor encontrado no 
segundo nível do perfil de inicialização fornecido. Esta característica gerava um grave erro nos cálculos da profundidade da camada limite, principalmente da CLN, cujos valores estimados pelo modelo eram extremamente baixos (da ordem de grandeza de 30 a 70 m, ou seja, valores típicos da Camada Superficial). Santos (2005) solucionou este problema, fornecendo um valor inicial de $\mathrm{h}_{\mathrm{i}}$ ao modelo para que este pudesse iniciar os cálculos - cabe ressaltar que neste trabalho foram utilizados os valores médios observados no horário de início da integração, para cada um dos sítios experimentais.

\subsection{Características das Simulações}

O modelo foi simulado no modo "off line" com dados dos três sítios experimentais, para 3 noites diferentes, escolhidas por serem as que representavam o conjunto mais adequado de condições ambientais: noite de 12 a 13/02/99, em RM; noite de 11 a 12/02/99, na Floresta e; noite de 08 a 09/02/99, na FNS. Duas simulações de controle (CONTROLE1 e CONTROLE2), representativas de dois períodos de tempo distintos, foram rodadas para cada sítio experimental, comparadas com situações reais observadas em campo e usadas como padrão para descrever a evolução da CLN sob condições típicas de desenvolvimento. Em seguida, foram realizados quatro experimentos de sensibilidade, cujos resultados foram comparados com as simulações de controle, com o intuito de investigar a evolução da profundidade e estrutura da CLA durante a noite, sob diferentes condições de desenvolvimento da CLN. Ao todo, foram executadas seis simulações para cada sítio experimental, com as seguintes características:

- CONTROLE1 $\Rightarrow$ todas as rodadas iniciando às $17 \mathrm{hl}(21$ GMT), abrangendo deste modo o período de transição da CLC para a CLN, que se dá entre as 17 e $18 \mathrm{hl}$; período de integração do modelo de 15 horas, com intervalos de tempo de integração de 180 segundos (3 minutos); condições típicas de desenvolvimento da CLN, com noite de céu claro ( $\mathrm{Rn}$ médio em torno de $-50 \mathrm{~W} \cdot \mathrm{m}^{-2}$ ), com ventos calmos (de 1,0 a $1,5 \mathrm{~m} \cdot \mathrm{s}^{-1}$, ou menor) e sem ocorrência de chuvas; utilizando os parâmetros da TABELA 1.

- CONTROLE2 $\Rightarrow$ características semelhantes às apresentadas pela simulação CONTROLE1 - período de integração de 15 horas, com intervalos de 180 segundos (3 minutos), também utilizando os parâmetros da TABELA 1, e para as mesmas condições de desenvolvimento - entretanto, todas as rodadas foram iniciadas às $19 \mathrm{hl}$ (23 GMT), para que a evolução da CLN pudesse ser estudada a partir de condições noturnas já estabelecidas.

- EXP1 $\Rightarrow$ Noite parcialmente nublada (cerca de 4/8 do céu encoberto), com ventos calmos (1-2 $\mathrm{m} \cdot \mathrm{s}^{-1}$, ou menor) e sem ocorrência de chuvas.
- $\mathrm{EXP} 2 \Rightarrow$ Noite nublada (8/8 do céu encoberto), com ocorrência de chuva contínua ao longo da madrugada $-7,2 \mathrm{~mm}$. $\mathrm{h}^{-1}$, durante 4 horas seguidas.

- EXP3 $\Rightarrow$ Noite parcialmente nublada (6/8 do céu encoberto), com ocorrência de chuva isolada no final da tarde $-10,8 \mathrm{~mm}$ durante 30 minutos.

- EXP4 $\Rightarrow$ Noite de céu claro, com ocorrência de um máximo relativo na velocidade do vento $\left(\geq 5 \mathrm{~m} \cdot \mathrm{s}^{-1}\right)$ abaixo dos $1000 \mathrm{~m}$ de altura (jato noturno).

A exceção da simulação EXP4, que utilizou perfis de radiossonda, com a finalidade de captar os sinais do $\mathrm{JN}$, todas as outras simulações foram executados utilizando os perfis obtidos a partir das sondagens com balão cativo.

\section{RESULTADOS E DISCUSSÃO}

\subsection{Simulações de controle}

Os resultados das duas simulações de controle realizadas durante as três noites selecionadas citadas anteriormente - CONTROLE1 e CONTROLE2 - foram comparados com dados observados e entre si. As variações do saldo de radiação simulado e dos fluxos simulados de calor sensível, calor latente e calor no solo, para estas simulações são ilustradas nas Figuras 1, 2 e 3.

As análises de CONTROLE1 mostram que, tanto em RM como na Floresta, o saldo de radiação $(\mathrm{Rn})$ foi bem estimado para o período noturno - entre 21 e 06 hl, quando a CLN já está totalmente estabelecida - e no início da manhã após o nascer do sol (entre 06 e $07 \mathrm{hl}$ ); subestimado - em média, cerca de -45 e $-50 \mathrm{~W} \cdot \mathrm{m}^{-2}$, em RM e na Floresta, respectivamente - no início da noite (entre 18 e 20 hl, em RM e 17 e 18 hl, na Floresta); e superestimado, aproximadamente em $33 \%$, durante o período de transição da mistura convectiva diurna para a fase estável noturna (entre 17 e $18 \mathrm{hl}$ ). Já na FNS, o saldo de radiação é subestimado (em torno de $-110 \mathrm{~W} \cdot \mathrm{m}^{-2}$ ) no final da tarde e início da noite (entre 17 e $19 \mathrm{hl})$ e durante a madrugada $(\sim-20 \mathrm{~W}$. $\mathrm{m}^{-2}$ ) pouco antes do nascer do sol, entre 04 e $05 \mathrm{hl}$ (Figuras 1a, 2a e 3a).

Estas tendências, embora mais suavizadas, continuaram a aparecer durante o experimento CONTROLE2 (cuja integração iniciava às $19 \mathrm{hl}$ ). As curvas do saldo de radiação em RM e na Floresta mostraram um valor subestimado durante a primeira metade da noite em cerca de $25 \mathrm{~W} \cdot \mathrm{m}^{-2}$, ajustando-se após as 22 hl (em RM) e após 00 hl (sobre a Floresta). Na FNS o saldo de radiação estimado oscilou bastante em relação ao valor observado - embora, tenha se mantido, em média, cerca de $3 \mathrm{~W} . \mathrm{m}^{-2}$ acima dos valores observados - até a meia-noite; após este horário, houve um ajuste que se prolongou até o início da manhã (próximo das $06 \mathrm{hl}$ ), quando o valor de $\mathrm{Rn}$, calculado pelo modelo, passa a ser superestimado em relação aos valores observado (Figuras 1b, 2b e 3b). 

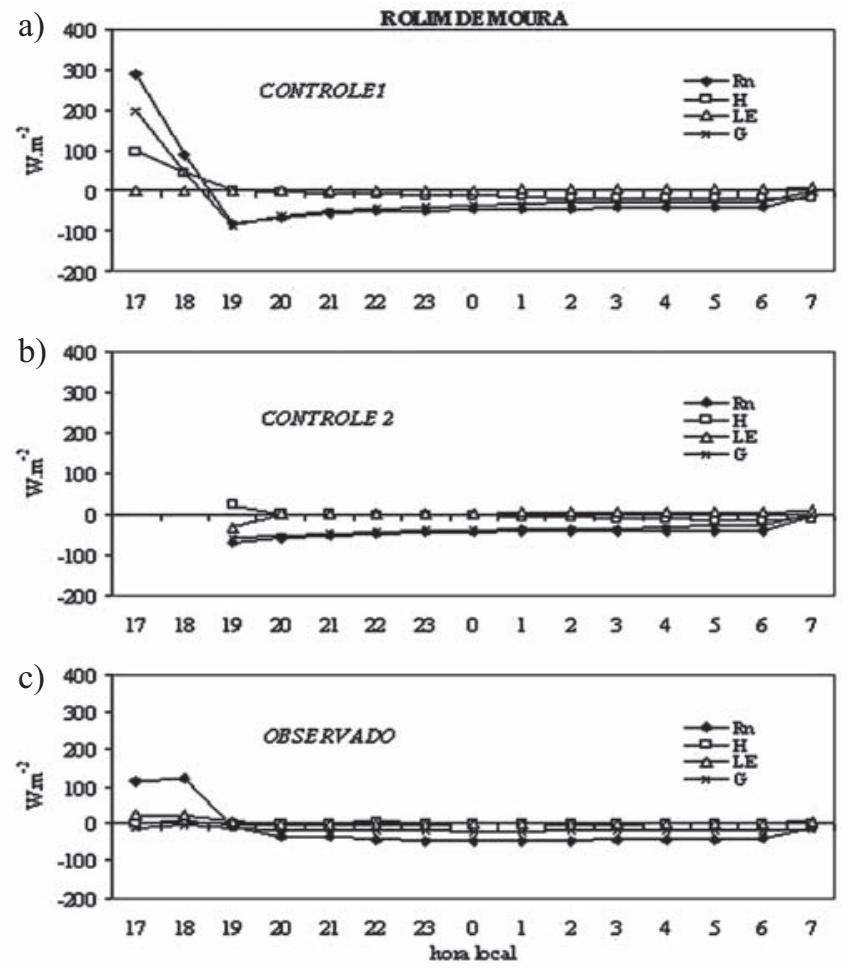

Figura 1 - Saldo de Radiação (Rn), Fluxos de calor sensível (H), calor latente (LE) e calor no solo (G) em Rolim de Moura: (a) simulados para CONTROLE1, (b) simulados para CONTROLE2 e (c) observados na noite de 12 a 13/02/99.
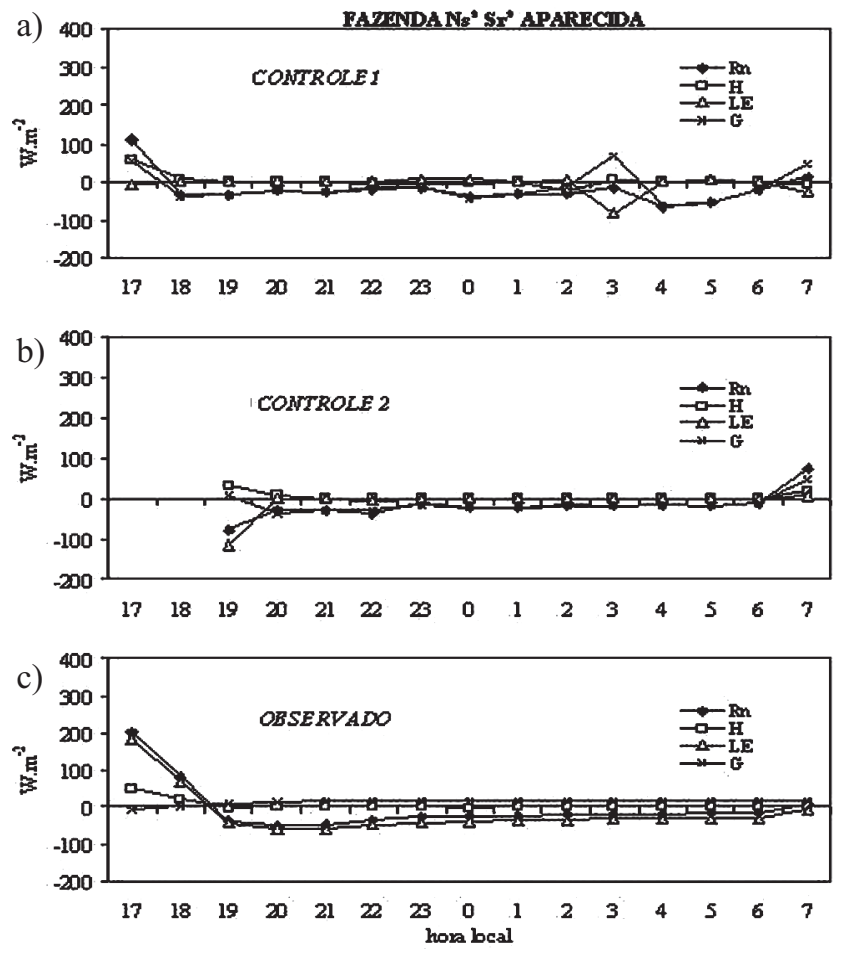

Figura 3 - Saldo de Radiação (Rn), Fluxos de calor sensível (H), calor latente (LE) e calor no solo (G) na FNS: (a) simulados para CONTROLE1, (b) simulados para CONTROLE2 e (c) observados na noite de 08 a 09/02/99.
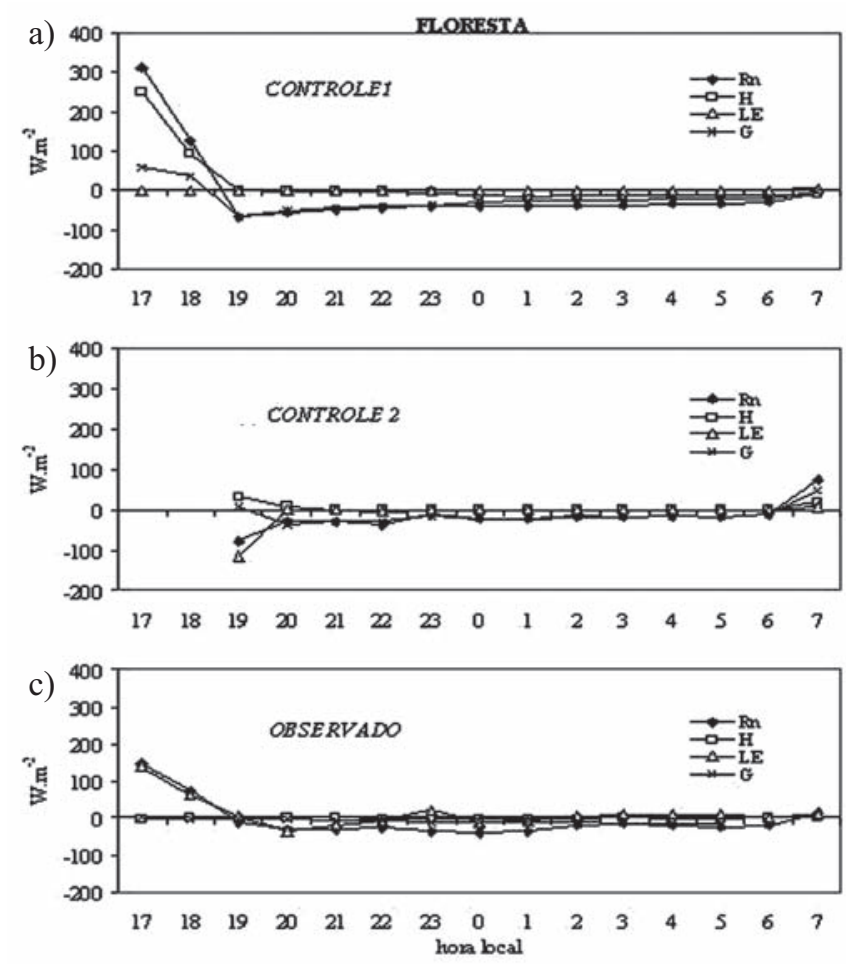

Figura 2 - Saldo de Radiação (Rn), Fluxos de calor sensível (H), calor latente (LE) e calor no solo (G) Na Floresta: (a) simulados para CONTROLE1, (b) simulados para CONTROLE2 e (c) observados na noite de 11 a 12/02/99.

Os fluxos de calor sensível (H) e latente (LE) foram razoavelmente bem representados em RM e na Floresta, durante o período em que a CLN já se encontra estabelecida (entre 20 e $06 \mathrm{hl}$ ), com valores bem próximos aos observados - situação observada tanto para o CONTROLE1 (Figuras 1a e 2a) como para o CONTROLE2 (Figuras 1b e 2b). Entretanto, durante a transição vespertina e no início da noite, quando a turbulência atmosférica começa a diminuir e tem início o resfriamento da superfície após o pôr-do-sol, os valores de H são superestimados e os de LE subestimados, com relação aos observados. Tal situação foi notada principalmente na Floresta, o que pode estar, de alguma forma, relacionado à ausência da representação da energia armazenada pela biomassa nos termos do balanço de energia no modelo.

Esta situação é um pouco diferente na FNS, onde $\mathrm{H}$ simulado concorda quase que totalmente com os valores observados durante todo o período de integração (para ambos, CONTROLE1 e CONTROLE2); enquanto que LE é superestimado (provavelmente devido aos altos valores de umidade do perfil inicial) - em torno de $40 \mathrm{~W} \cdot \mathrm{m}^{-2}$ - durante a maior parte da noite e subestimado (em aproximadamente $-95 \mathrm{~W} \cdot \mathrm{m}^{-2}$ ) durante a transição vespertina (Figura 3). Em geral, no caso do saldo de radiação e dos fluxos turbulentos de calor latente e sensível para as condições de umidade do período estudado, o modelo 
mostrou a tendência de iniciar com valores bem discrepantes (acima ou abaixo) em relação aos valores observados, mas ajustou-se ao longo da integração, para ambas as simulações. Este tempo de ajuste foi da ordem de 2 horas do início da integração para a simulação CONTROLE1, e cerca de 1 hora do início da integração, para a simulação CONTROLE2. No caso do fluxo de calor no solo - G, de um modo geral, seu valor foi superestimado na transição da fase convectiva (diurna) para a estável (noturna) e no início da manhã, e subestimado no início da noite e durante a madrugada (aproximadamente entre 19 e 06 hl), para os três os sítios experimentais.

Essas características também foram notadas em estudos anteriores realizados por Murthy et al. (2004), com uma versão do OSU-CAPS, para uma região tropical localizada no Noroeste da Índia. Os autores observaram que, para condições úmidas naquela região, o saldo de radiação e os fluxos de calor sensível, latente e no solo não eram bem representados, e sugeriram a necessidade de modificações na formulação do fluxo de calor no solo inserida no modelo. Apesar disso, ao comparar a variação dos fluxos estimados neste estudo às curvas encontradas por Murthy et al. (2004), nota-se que para o caso de Rondônia a representação está bem melhor ajustada.
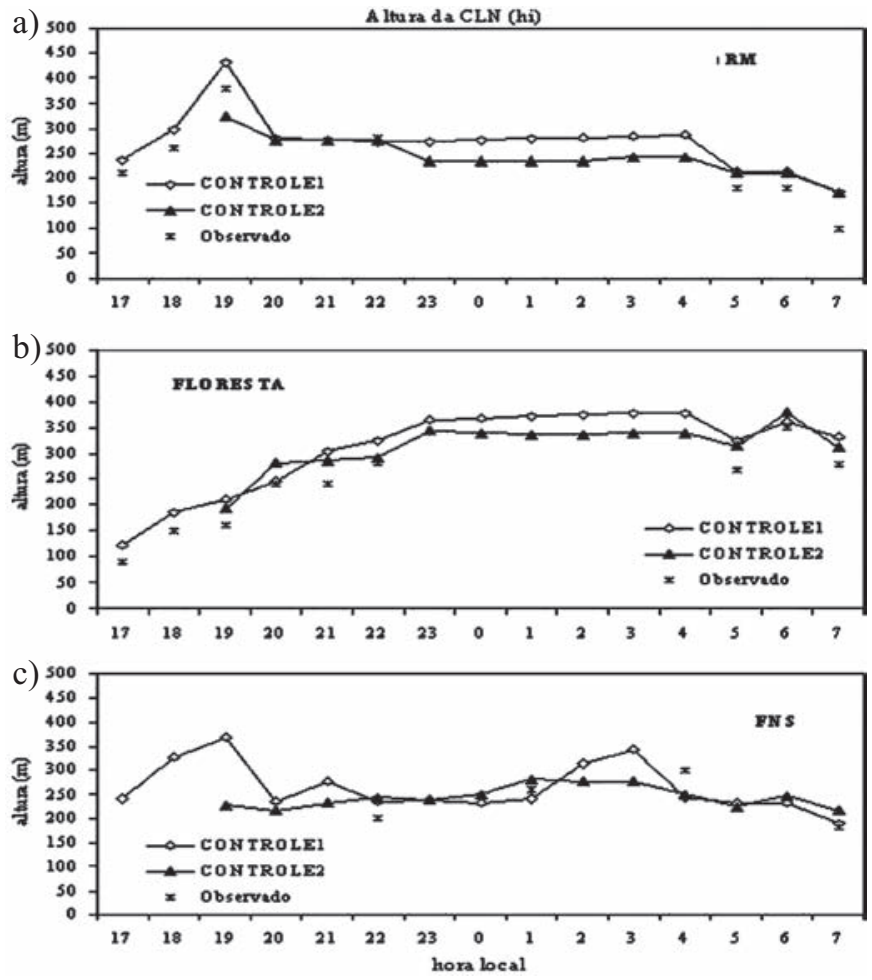

Figura 4 - Altura da CLN $\left(\mathrm{h}_{\mathrm{i}}\right)$ observada e simulada para CONTROLE1 e CONTROLE2: (a) em Rolim de Moura - RM; (b) na Floresta e; (c) na Fazenda $\mathrm{Ns}^{\mathrm{a}}$. $\mathrm{Sr}^{\mathrm{a}}$ Aparecida - FNS.
A profundidade da CLN $\left(\mathrm{h}_{\mathrm{i}}\right)$ simulada concorda relativamente bem com os valores observados nos três sítios de medidas (FIGURA4), em relação ao modo como se desenvolve ao longo do dia (forma de variação). Do ponto de vista numérico, entretanto, nota-se que os valores de $h_{i}$ estimados tendem a estar, aproximadamente, $20 \%$ acima dos valores observados.

$\mathrm{Na}$ Floresta, $\mathrm{h}_{\mathrm{i}}$ atingiu o máximo valor às $19 \mathrm{hl}-$ algo em torno de 420 e 410 m, para CONTROLE1 e CONTROLE2 (Tabelas 2 e 3), respectivamente, tornando a diminuir até as $20 \mathrm{hl}$ (quando assumiu valor próximo de $300 \mathrm{~m}$ ), permanecendo constante durante a madrugada até as $04 \mathrm{hl}$, quando apresenta um declínio suave até atingir seu valor mínimo as 07 hl (em torno de $190 \mathrm{~m}$ ). Em RM h $\mathrm{h}_{\mathrm{i}}$ tende a aumentar até as $23 \mathrm{hl}$, quando atinge seu máximo valor (em torno de $380 \mathrm{~m}$ ), permanecendo constante até as $05 \mathrm{hl}$; sendo que no caso de CONTROLE2 o valor máximo ocorre por volta de $06 \mathrm{hl}$ (aproximadamente 390 a $400 \mathrm{~m}$ ). Já na FNS, os valores de $\mathrm{h}_{\mathrm{i}}$, simulados pelo CONTROLE1, oscilaram entre 200 e $300 \mathrm{~m}$ ao longo do período, com dois máximos ocorrendo as 19 e $03 \mathrm{hl}$ (com valores em torno de 390 e $350 \mathrm{~m}$, respectivamente); em CONTROLE2 a variação de $h_{i}$ foi mais suave, com valor máximo próximo de $300 \mathrm{~m}$, ocorrendo por volta de $01 \mathrm{hl}$.

A relação entre a variação de $\mathrm{H}$ e o crescimento de $h_{i}$ - que é bem notada no final da tarde (CONTROLE1) e início da noite (CONTROLE2) - parece não funcionar bem durante o restante da noite (entre 20 e $06 \mathrm{hl}$ ), sugerindo que outros fatores, tais como geração de turbulência mecânica e o desacoplamento da superfície, podem estar contribuindo para o crescimento da CLN e não estão sendo bem representados no modelo, pois estes termos não estão explicitamente descritos.

Os perfis simulados de temperatura potencial $(\theta)$ para as duas simulações de controle foram comparados com os perfis observados nos três sítios (Figuras 5 e 6), utilizando-se como critério a altura da CLN $\left(\mathrm{h}_{\mathrm{i}}\right)$ definida em $\Delta \theta / \Delta \mathrm{z} \cong 0$. Em termos médios, a estrutura da CLN apresentada pelos perfis de temperatura potencial foi razoavelmente bem representada nas duas simulações, principalmente durante a madrugada e início da manhã - perfis de 05, 06, 07 e 08 hl (em RM e na Floresta), perfis de 01, 04 e $07 \mathrm{hl}$ (na FNS) - quando os perfis simulados de $\theta$ ilustram satisfatoriamente a evolução da CLN.

A simulação CONTROLE1 mostrou perfis de $\theta$, sobre a floresta e em RM, apresentando uma camada mais estável próxima à superfície, com temperaturas variando entre $294 \mathrm{~K}$ e $300 \mathrm{~K}$ e a inversão noturna bem definida, ocorrendo em torno dos 100 m; acima disso, observou-se a formação de uma camada bem misturada verticalmente (representada pela Camada Residual - CR) que se estendia até cerca de $500 \mathrm{~m}$. No caso da FNS, os perfis simulados tenderam a apresentar uma pequena camada estável nos primeiros metros acima da superfície e uma camada bem misturada, estendendo-se até cerca de 300 m (altura 
Tabela 2 - CONTROLE1 - Valores simulados: altura da CLN $\left(\mathrm{h}_{\mathrm{i}}\right)$, em m; fluxos de calor sensível, latente e no solo (H, LE e G, respectivamente), em W.m $\mathrm{m}^{-2}$; e Saldo de radiação $(\mathrm{Rn})$, em W.m ${ }^{-2}$.

\begin{tabular}{|c|c|c|c|c|c|c|c|c|c|c|c|c|c|c|c|}
\hline \multirow{2}{*}{ hora } & \multicolumn{5}{|c|}{ RM } & \multicolumn{5}{|c|}{ Floresta } & \multicolumn{5}{|c|}{ FNS } \\
\hline & $\mathbf{h}_{\mathbf{i}}$ & $\mathbf{H}$ & $\mathbf{F}$ & G & & $\mathbf{h}_{\mathbf{i}}$ & H & I & G & & 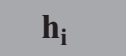 & $\mathbf{H}$ & $\mathbf{E}$ & G & n \\
\hline 17 & 237,3 & 96,9 & 0,0 & 197,1 & 292,7 & 123,0 & 252,8 & 0 , & 59,6 & 311,3 & 40,27 & 59,7 & $-6,3$ & 56,6 & 08,6 \\
\hline 18 & 295,6 & 45,7 & 0,0 & & & & & & & & & & 0 & 40,7 & 33,5 \\
\hline 19 & 32,8 & 00 & 0,7 & $-83,0$ & $-81,4$ & 10,9 & 0,0 & 0 & 管 & 67,7 & 0 & -0 & 0,1 & $-36,4$ & $-36,7$ \\
\hline 20 & o & $-2,9$ & , & $-62,8$ & - & - no & $-1,7$ & , & , & . & & s & 0,4 &, 4 & $-25,2$ \\
\hline 21 & 274,8 & $-5,0$ & 0,9 & $-51,0$ & $-55,2$ & 303,6 & $-3,3$ & 0,2 & $-45,0$ & $-48,2$ & 27 & 0 & 0,0 & $-29,1$ & $-29,1$ \\
\hline 22 & 273,8 & $-6,4$ & 1,5 & $-44,0$ & $-47,1$ & 323,3 & $-3,9$ & 0,3 & $-40,3$ & $-44,0$ & 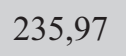 & -3, & 1,1 & $-16,5$ & $-18,7$ \\
\hline 23 & 274,2 & (5) & 2,1 & $-39,6$ & , nor & - & $-5,9$ & 列 & $-36,2$ & , & - & -8 & 6 , & $-14,0$ & $-15,5$ \\
\hline 00 & 275,4 & $-10,7$ & 3,0 & $-36,0$ & $-43,9$ & 366,2 & $-13,8$ & 1,2 & $-28,0$ & $-40,7$ & 232,01 & -4 & 9,6 & $-43,4$ & $-38,4$ \\
\hline 01 & 278,0 & $-14,4$ & 4,3 & $-32,9$ & $-43,1$ & $3 / 2,4$ & $-19,4$ & 2,3 & $-23,4$ & $-40,5$ &, 59 & , & 0,4 & $-30,7$ & $-30,3$ \\
\hline 02 & 281,4 & $-17,6$ & 4,3 & -28 & -4 & 373 & -13 & 1 & -25 & $-37,6$ & 21 & -22 & 3 , & -1 & -32 \\
\hline 03 & 284,8 & $-17,4$ & 4,7 & $-28,2$ & $-41,0$ & 376,1 & $-12,1$ & 1,0 & $-23,8$ & $-34,8$ & 342,38 & 2,4 & $-84,1$ & 65,0 & $-16,8$ \\
\hline 04 & 201,2 & $-17,0$ & 4,9 & $-28,2$ & $-40,4$ & 377,2 & $-11,2$ & 1,0 & $-21,9$ & $-32,1$ & & $-1,4$ & 0,9 & $-64,4$ & -64 \\
\hline 05 & 214,0 & 7,6 & 5,2 & $-27,4$ & $-39,8$ & 324,4 & $-11,0$ & 0, & -21 & i & ( & $-1,7$ & 2,6 & $-55,3$ & $-54,4$ \\
\hline 06 & 210,0 & $-17,8$ & 5,2 & $-26,8$ & $-39,5$ & 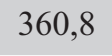 & $-11,3$ & 0,9 & $-20,1$ & $-30,5$ & & 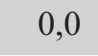 & 0,0 & $-21,0$ & 21 \\
\hline 07 & 172,4 & $-16,0$ & 7,3 & $-1,5$ & $-10,2$ & 332,2 & $-8,2$ & 3,7 & $-1,0$ & $-5,6$ & 189,77 & $-7,0$ & $-29,1$ & 47,3 & 11,3 \\
\hline
\end{tabular}

Tabela 3 -CONTROLE2 - Valores simulados: altura da CLN $\left(\mathrm{h}_{\mathrm{i}}\right)$, em m; fluxos de calor sensível, latente e no solo (H, LE e G, respectivamente), em W.m ${ }^{-2}$; e Saldo de radiação (Rn), em W.m.

\begin{tabular}{|c|c|c|c|c|c|c|c|c|c|c|c|c|c|c|c|}
\hline \multirow{2}{*}{ hora } & \multicolumn{5}{|c|}{ Rolim de Moura } & \multicolumn{5}{|c|}{ Floresta } & \multicolumn{5}{|c|}{ Fazenda $\mathrm{N}^{\mathrm{sa}} \mathrm{Sr}^{\mathrm{a}}$ Aparecida } \\
\hline & $\mathbf{h}_{\mathbf{i}}$ & $\mathbf{H}$ & $\mathbf{L E}$ & G & $\mathbf{R n}$ & $\mathbf{h}_{\mathbf{i}}$ & H & $\mathbf{L E}$ & G & $\mathbf{R n}$ & $\mathbf{h}_{\mathbf{i}}$ & H & LE & G & $\mathbf{R n}$ \\
\hline 19 & 322,58 & 23,5 & $-32,5$ & $-60,1$ & 9,2 & 193,16 & 95,9 & $-44,1$ & 22,5 & 1,0 & 227,91 & 33,0 & 115,8 & 7,0 & 76,9 \\
\hline 20 & 274,99 & $-0,7$ & 0,0 & $-56,8$ & $-57,5$ & 280,18 & $-0,1$ & 0,0 & $-57,9$ & $-57,9$ & 216,92 & 7,3 & 0,3 & $-35,2$ & $-27,8$ \\
\hline 21 & 274,95 & $-1,0$ & 0,2 & $-49,7$ & $-50,5$ & 287,66 & $-2,2$ & 0,1 & $-49,3$ & $-51,4$ & 231,11 & 0,1 & 0,4 & $-28,7$ & $-28,2$ \\
\hline 22 & 274,90 & $-2,5$ & 0,6 & $-44,5$ & $-46,5$ & 291,83 & $-3,5$ & 0,1 & $-43,9$ & $-47,3$ & 242,65 & $-0,7$ & $-4,1$ & $-30,9$ & -35, \\
\hline 23 & 234,87 & $-3,5$ & 1,0 & $-41,8$ & 3 & 343 & $-5,7$ & 0, & $-39,1$ & $-44,6$ & 237,92 & 0 & 0,9 & $-13,7$ & -12 \\
\hline 00 & 234,85 & $-4,4$ & 1,5 & $-39,9$ & $-42,8$ & 339,58 & $-12,0$ & 0,2 & $-30,6$ & $-42,4$ & 249,73 & $-0,2$ & 0,2 & $-23,4$ & $-23,4$ \\
\hline 01 & 234,83 & $-5,6$ & 2,0 & $-38,4$ & $-42,1$ & 337,44 & $-9,7$ & 0,4 & $-27,4$ & $-36,7$ & 280,08 & 0,1 & 0,2 & $-20,9$ & $-20,7$ \\
\hline 02 & 234,8 & $-7,4$ & 2,7 & $-36,8$ & $-41,5$ & $33^{\circ}$ & $-6,8$ & 0,4 & -2 & $-31,5$ & 27 & 0,3 & 8 & $-16,8$ & -15 , \\
\hline 03 & 241,39 & $-9,4$ & 3,7 & $-35,6$ & $-41,3$ & 338,89 & $-5,8$ & 0,8 & $-24,0$ & $-29,0$ & 276,45 & 0,4 & 0,6 & $-19,3$ & $-18,2$ \\
\hline 04 & 241,35 & $-12,4$ & 4,0 & $-31,5$ & $-40,0$ & 338 & $-6,6$ & 0,3 & $-21,6$ & $-27,8$ & 249,76 & $-0,1$ & 0,4 & $-16,5$ & $-16,2$ \\
\hline 05 & 211,69 & $-13,8$ & 4,7 & $-30,5$ & $-39,6$ & 31 & $-6,7$ & 0,3 & $-21,0$ & $-27,4$ & 20 & $-0,1$ &, 5 & $-17,8$ & $-17,4$ \\
\hline 06 & 212,13 & $-14,1$ & 5,1 & $-30,2$ & $-39,2$ & 378,88 & $-7,1$ & 0,3 & $-20,3$ & $-27,2$ & 196,19 &, 1 & 6 & $-11,0$ & $-10,3$ \\
\hline 07 & 172,58 & $-11,6$ & 7,6 & $-5,2$ & $-9,2$ & 311,63 & $-4,5$ & 2,7 & $-5,0$ & $-6,8$ & 217,17 & 18,7 & 8,0 & 46,8 & 73,4 \\
\hline
\end{tabular}


da inversão térmica) e, acima disso uma CR bem definida foi formada - situação tipicamente observada no desenvolvimento da CLN sobre áreas urbanas - um pouco diferente da situação observada naquela área, em que a camada estável foi mais profunda e a inversão noturna ocorreu entre 200 e 250 m.
A simulação CONTROLE2 representou melhor o desenvolvimento da CLN, sobre os 3 sítios experimentais, descrevendo de forma satisfatória a sua estrutura, sobretudo na floresta, onde a evolução da CLN durante a madrugada e início da manhã (entre 05 e 08 hl) foi muito bem representada.
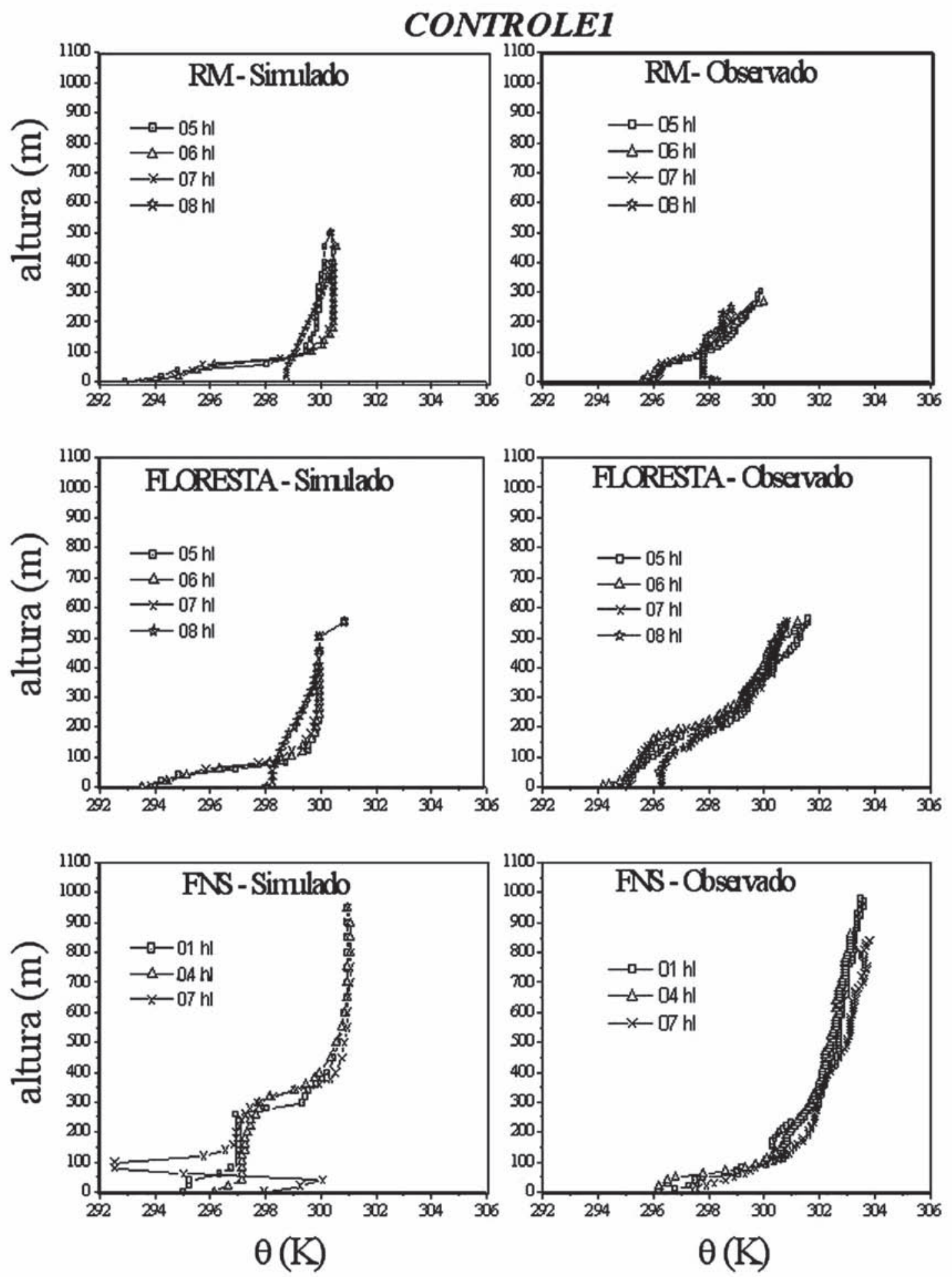

Figura 5 - Perfis da temperatura potencial $(\theta)$ sobre RM, a Floresta e FNS: CONTROLE1 x Observado. 
CONTROLE2
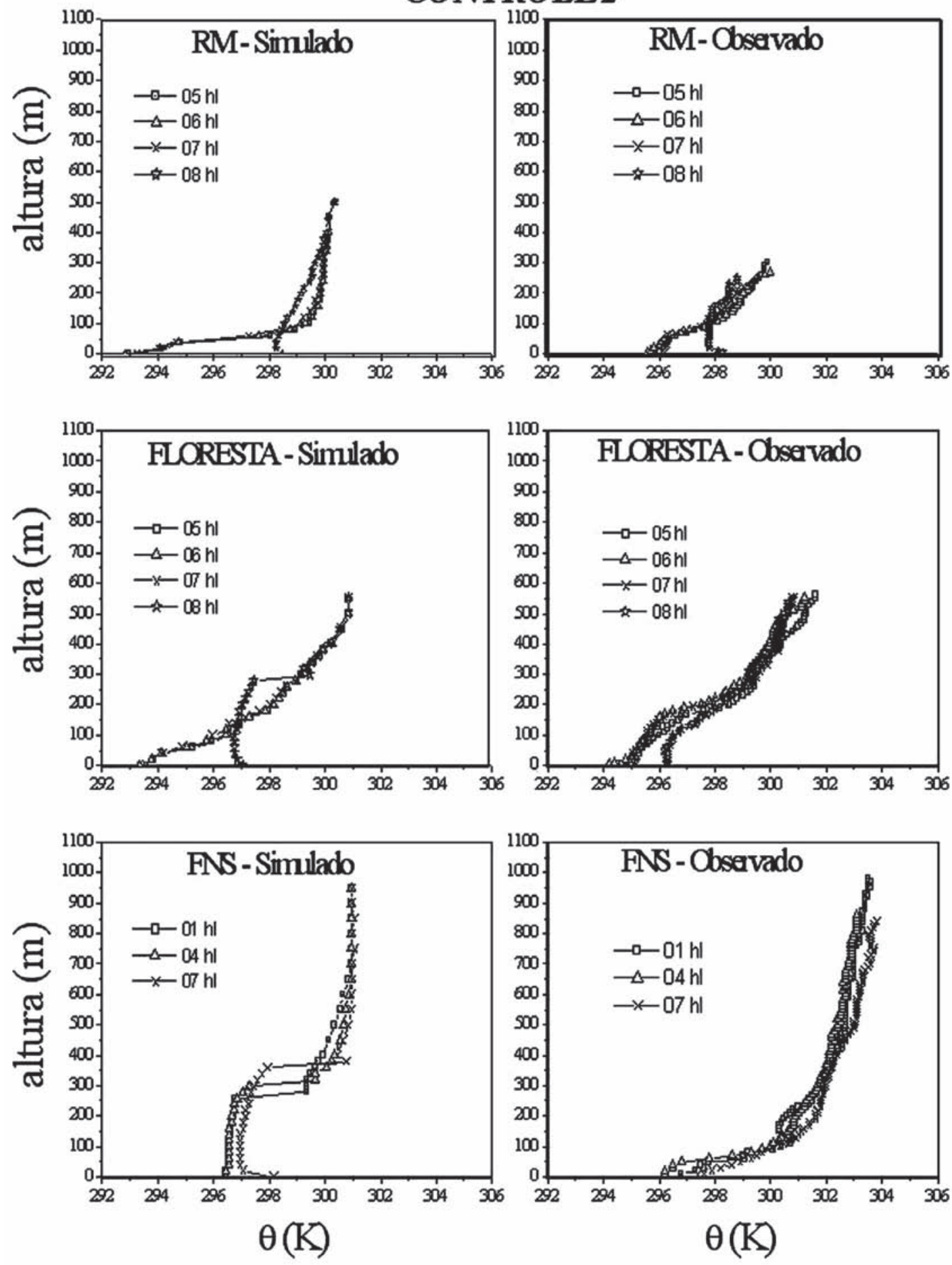

Figura 6 - Perfis da temperatura potencial $(\theta)$ sobre RM, a Floresta e FNS: CONTROLE2 x Observado. 


\subsection{Experimentos de sensibilidade}

Apesar das limitações do modelo em descrever a estrutura da CLA, este pôde ser utilizado para investigar a evolução e estrutura da CLN sob determinadas condições de desenvolvimento. A Figura 07 mostra a evolução da CLN ao longo da noite para as situações simuladas em EXP1, EXP2 e EXP4, para cada sítio. No caso da floresta e de RM, a diferença entre os experimentos foi muito pouca - ou quase nenhuma, ao se comparar apenas EXP1 e EXP2. A altura da inversão noturna variou entre 220 e $260 \mathrm{~m}$ e no intervalo entre 23 e $02 \mathrm{hl}$, em $\mathrm{RM}$, foi ligeiramente maior para o caso que simula a presença do jato (EXP4). Na floresta, $h_{i}$ foi menor na presença do jato ao longo de quase todo o período. Portanto, deduz-se que sobre os sítios com áreas desmatadas (RM e FNS), durante eventos de jato, a turbulência mecânica contribui mais efetivamente para o aprofundamento da CLN, dominando a organização de sua estrutura; enquanto na floresta parece não haver um mecanismo predominante bem definido, sugerindo que, mesmo na presença do jato, o resfriamento radiativo ainda desempenha um papel importante sobre a dinâmica da CLN, funcionando como um inibidor da turbulência.

As simulações na FNS foram as que apresentaram as maiores diferenças, com $\mathrm{h}_{\mathrm{i}}$ oscilando bastante ao longo da noite, nas 3 simulações. Os menores valores foram apresentados por
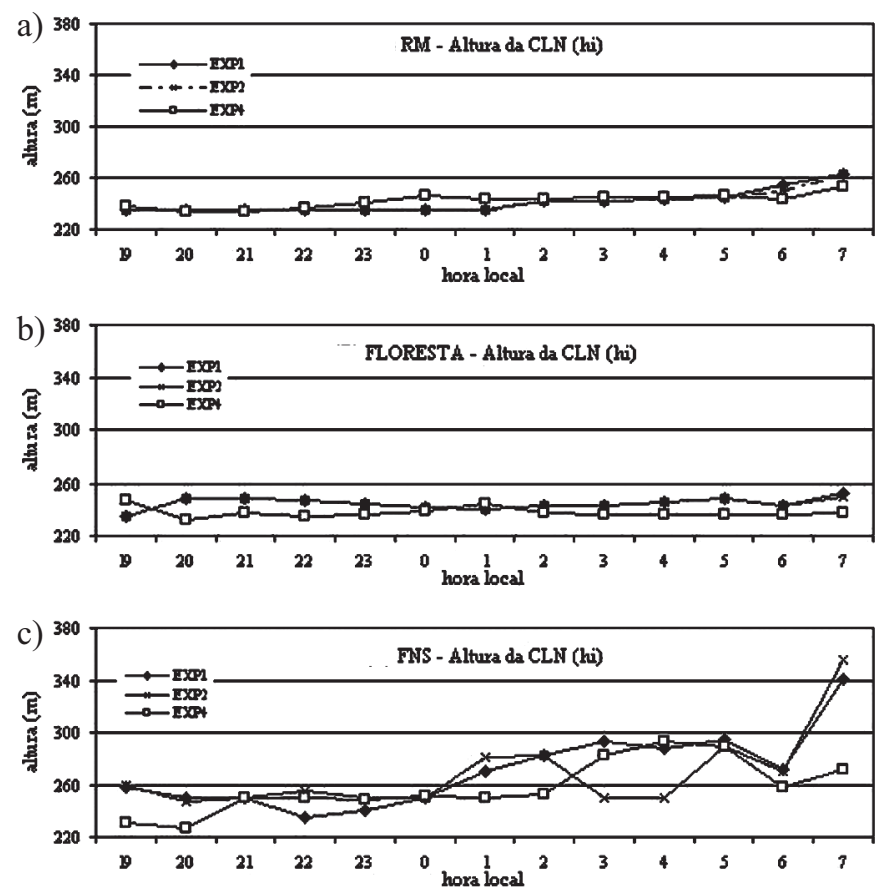

Figura 7 - Altura da CLN (hi) simulada pelo modelo, durante os experimentos EXP1, EXP2 e EXP4: (a) em RM; (b) na Floresta e; (c) na FNS.
EXP4 no início da noite ( $220 \mathrm{~m}$, as $20 \mathrm{hl})$ e o máximo valor simulado de $\mathrm{h}_{\mathrm{i}}$ ocorreu no início da manhã (cerca de 340 - $350 \mathrm{~m}$, as $07 \mathrm{hl}$ ) para as simulações EXP1 e EXP2. No caso de EXP2, nota-se que a maior variação de $h_{\mathrm{i}}$ ocorre após as $00 \mathrm{hl}$ - horário do início da precipitação determinado no modelo.

Durante a simulação EXP3 - realizada com a condição de ocorrência de precipitação no início da integração - também foi observada a tendência da Floresta e de RM apresentarem comportamentos semelhantes no que se refere ao crescimento da CLN (Figura 8), exceto nos períodos das transições vespertina e matutina (final da tarde e início da manhã, respectivamente). Nota-se para estes períodos que o modelo mostra uma variação maior de $h_{i}$, para os três sítios, alcançando valores entre 213 e 247 m, na floresta, 190 e 247 m, em RM e, 200 e 240 m, na FNS, no final da tarde. No decorrer da noite, na floresta e em RM a profundidade da CLN é praticamente constante, voltando a haver crescimento próximo do horário de nascer do sol (em torno de $5 \mathrm{hl}$ ). Já a FNS apresenta um pico de desenvolvimento entre 00 e $01 \mathrm{hl}$ (cerca de $300 \mathrm{~m}$ ), que coincide com um pequeno aumento na velocidade do vento à superfície.

Quanto à estrutura vertical, as Figuras 9 a 11 ilustram os perfis verticais de temperatura potencial $(\theta)$, simulados pelos 4 experimentos, para cada sítio. A simulação EXP1 apresenta para RM a CLN com topo razoavelmente bem identificado - em torno de $200 \mathrm{~m}$ (se considerarmos $\mathrm{h}_{\mathrm{i}}$ definido em $\Delta \theta / \Delta \mathrm{z} \cong 0$ ); a $\mathrm{CR}$ é melhor identificada nos perfis de $00 \mathrm{a} 05 \mathrm{hl}$ e uma camada bem misturada rasa aparece abaixo de $100 \mathrm{~m}$ no início da manhã (horário da erosão). Sobre a floresta, até as $00 \mathrm{hl}$ a camada se encontra estratificada em 3 partes - uma primeira camada mais estável próximo à superfície (onde o resfriamento radiativo é o fator preponderante); uma mistura rasa entre 50 e $150 \mathrm{~m}$ (onde predomina a turbulência mecânica) e, acima disso, outra camada também estável, porém com gradiente menor - e a CR pode ser observada acima dos $400 \mathrm{~m}$. A partir de $01 \mathrm{hl}$, a estratificação torna-se mais estável em toda a camada e o gradiente aumenta de forma constante, indicando que o resfriamento da superfície se torna o mecanismo de controle dominante. Sobre a FNS a CLN,

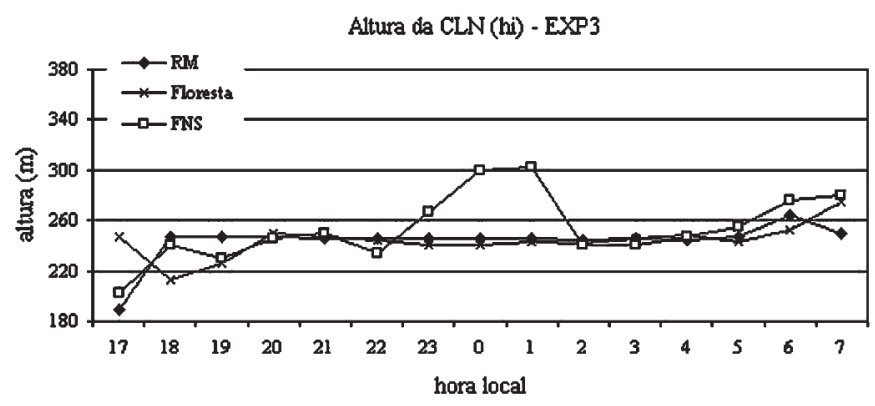

Figura 8 - Profundidade da CLN (hi) estimada pelo modelo, durante a simulação EXP3, para os 3 sítios estudados. 
basicamente, está dividida em 2 camadas bem visíveis: uma bem misturada próximo à superfície que começa bem rasa (abaixo de $100 \mathrm{~m}$ ) e aumenta gradativamente ao longo da noite, atingindo cerca de $300 \mathrm{~m}$ as $4 \mathrm{hl}$ (situação típica de áreas urbanas); e outra mais estável, com gradiente aumentando até aproximadamente $500 \mathrm{~m}$. A CR torna-se mais nítida nos perfis de 02 as $04 \mathrm{hl}$.

No caso das simulações EXP2 e EXP3, a estrutura da CLN apresenta características semelhantes, especialmente sobre a Floresta e RM, com uma camada estável rasa no início da noite, com características de ventos calmos e pouca (ou nenhuma) turbulência, se aprofundando durante a madrugada e ainda mantendo essa tendência de manhã cedo (perfil de $07 \mathrm{hl}$ ). Nestas condições, a CLN apresentou-se dividida em duas camadas - a camada superficial (CS) e a CR - e foi dominada, sobretudo durante a madrugada (entre $00 \mathrm{e} 05 \mathrm{hl}$ ), pelo resfriamento da superfície. Sobre a FNS, a CLN permanece com características de áreas urbanas e uma camada de mistura rasa começa a se formar no início da noite, ganhando força durante a madrugada e dividindo a CLN em duas camadas bem definidas, abaixo e acima da mistura.
Em EXP4, para a FNS, esta mistura também aparece, no entanto seu desenvolvimento ao longo da noite é pequeno, mantendo uma camada bem misturada constante de, aproximadamente, $200 \mathrm{~m}$ de espessura abaixo do jato, caracterizando bem o desacoplamento em relação à superfície. Sobre a floresta e em RM os perfis de $\theta$ apresentaram características de desenvolvimento típicas de noites com atividade turbulenta, $\operatorname{com} \Delta \theta / \Delta z$ diminuindo acentuadamente com a altura. Nos três sítios a turbulência mecânica gerada devido à presença do jato predominou durante toda a noite, sendo a principal responsável pela estratificação da CLN.

Os perfis de vento estimados pela simulação EXP4 - que considera a ocorrência de um jato no perfil inicial, em torno de $600 \mathrm{~m}$ de altura - para RM, floresta e FNS (Figura 3.20), mostram que o aparecimento deste jato causa uma perturbação que se reflete nos níveis mais baixos, intensificando os ventos próximos à superfície e, provavelmente, dando origem a movimentos turbulentos, os quais, no caso especial da FNS, provocam o aparecimento da camada bem misturada observada próximo à superfície e o desacoplamento da camada superior. 


\section{EXP1}
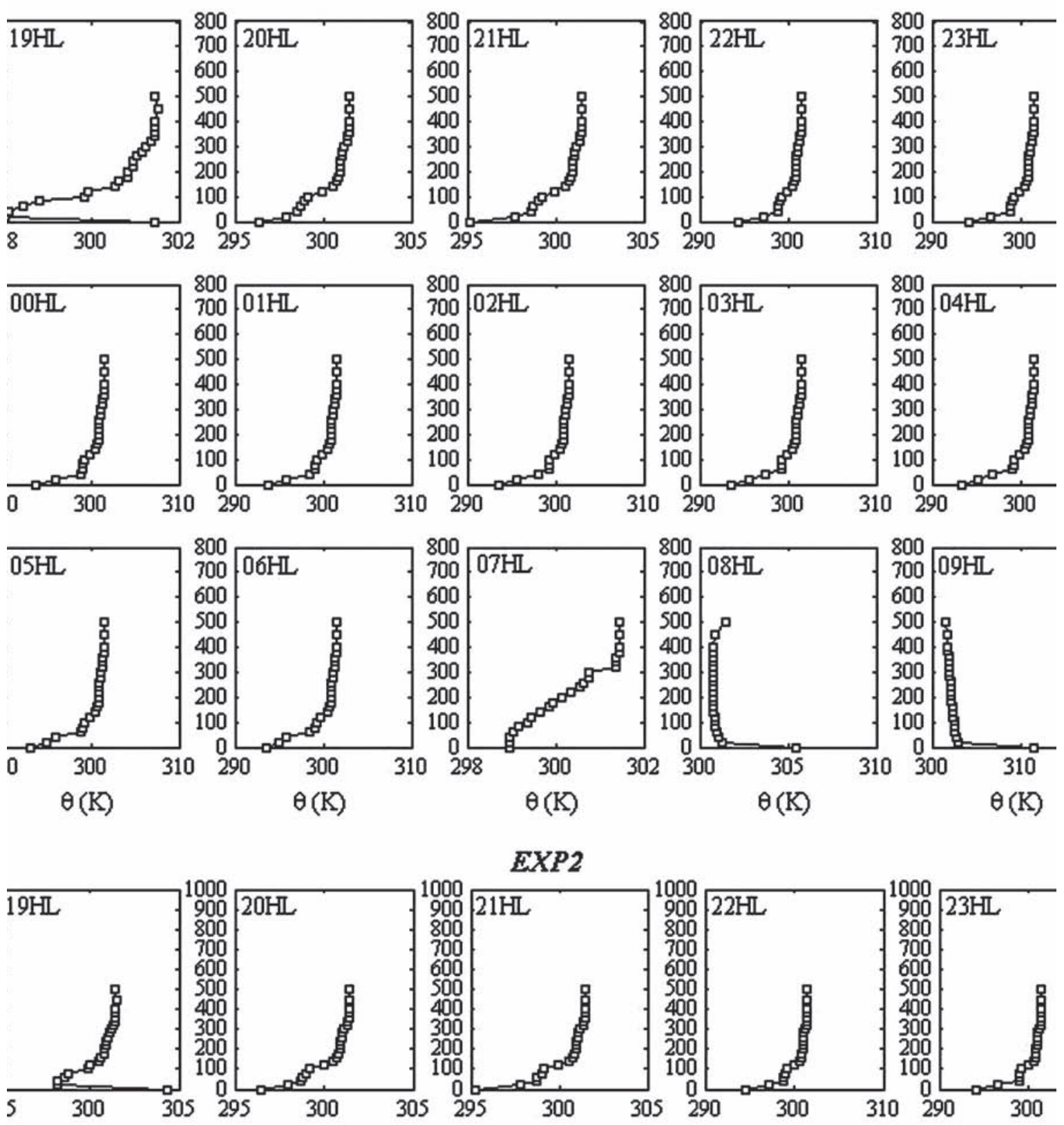

\section{EXP2}
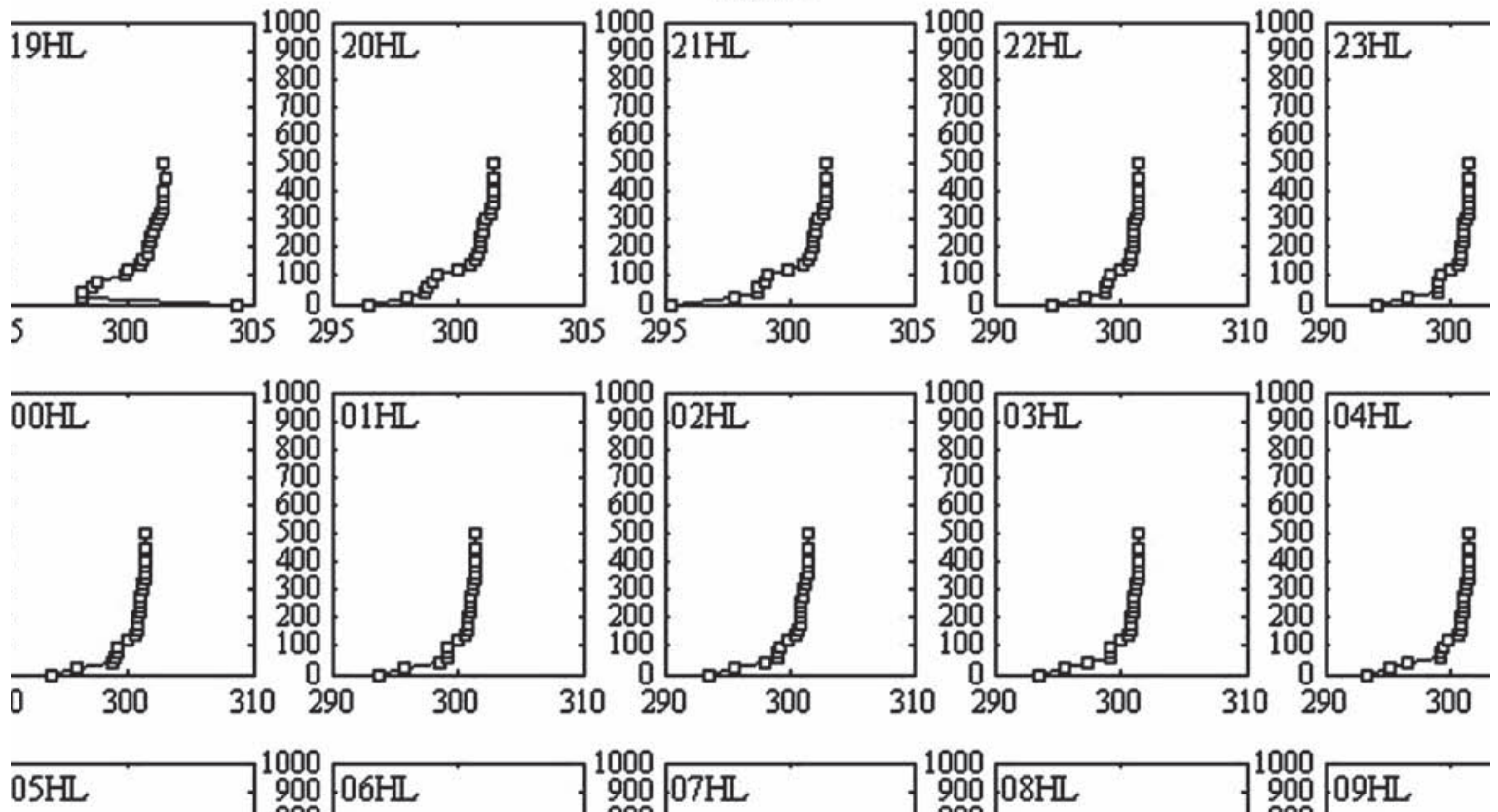

Figura 9 - Perfis horários de temperatura potencial $(\theta)$, obtidos pelas simulações EXP1, EXP2, EXP3 e EXP4, para RM. 

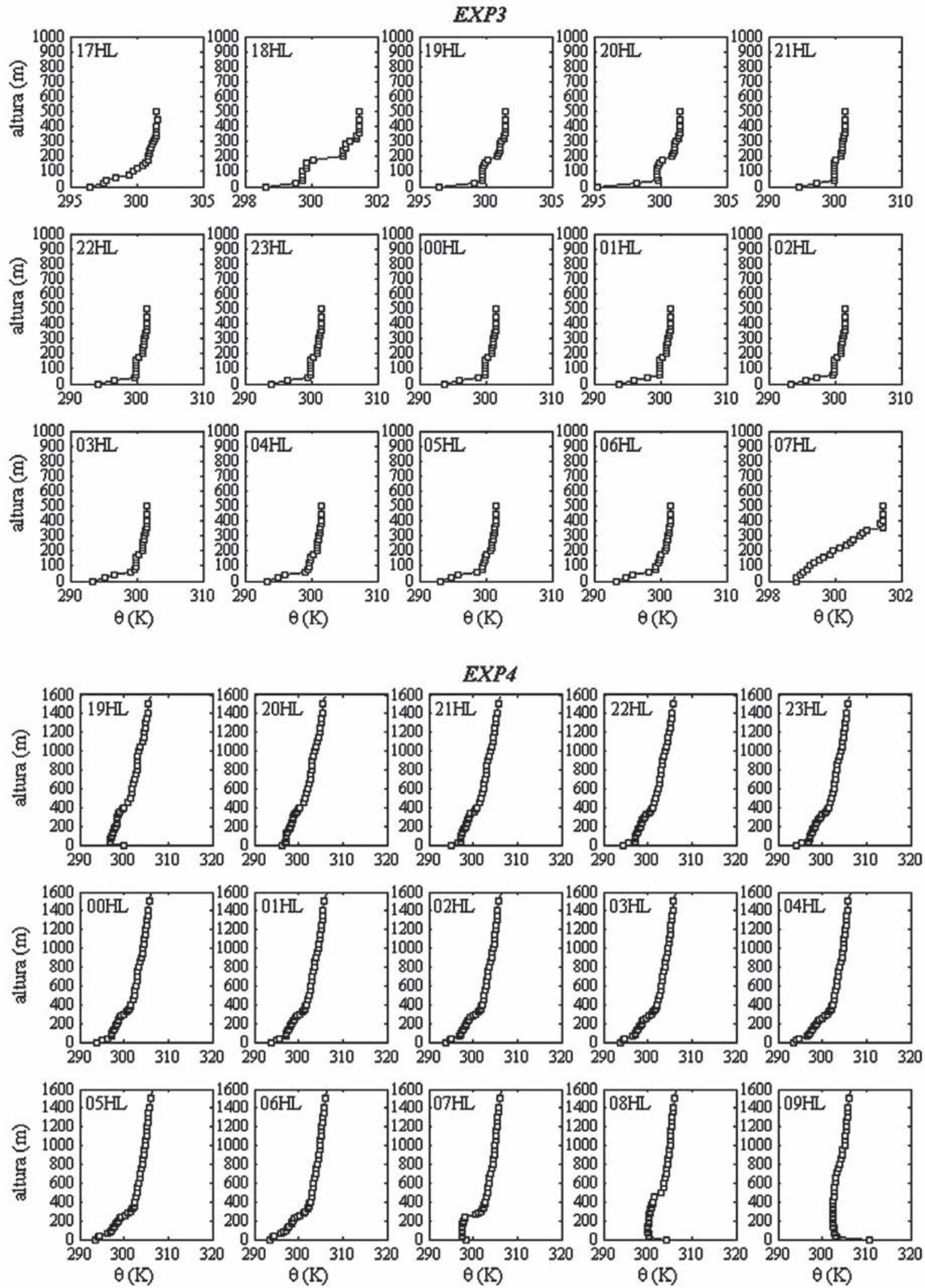

Figura 9 - Perfis horários de temperatura potencial ( $\theta$ ), obtidos pelas simulações EXP1, EXP2, EXP3 e EXP4, para RM (Continuação). 

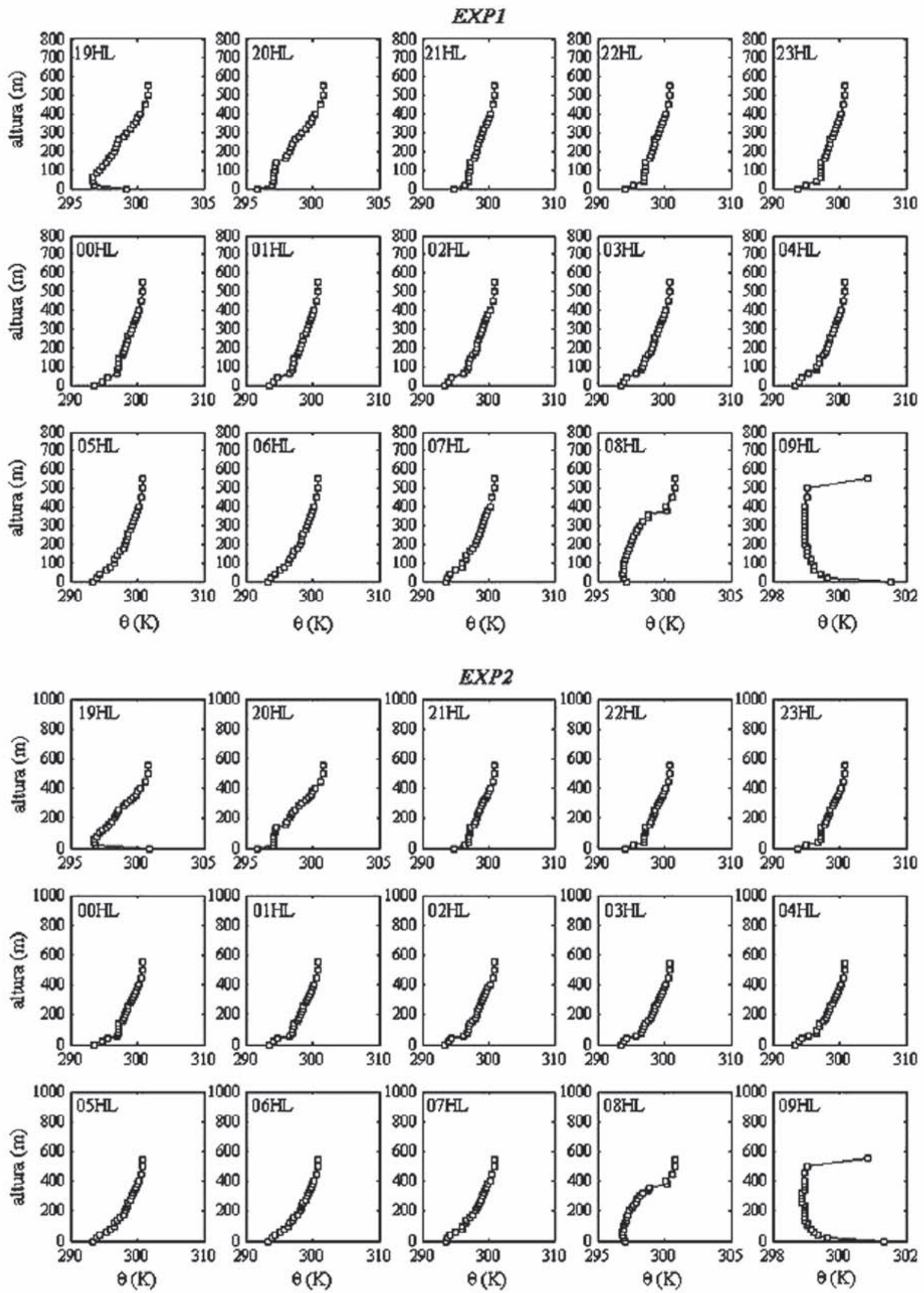

Figura 10 - Perfis horários de temperatura potencial $(\theta)$, obtidos pelas simulações EXP1, EXP2, EXP3 e EXP4, para a Floresta. 

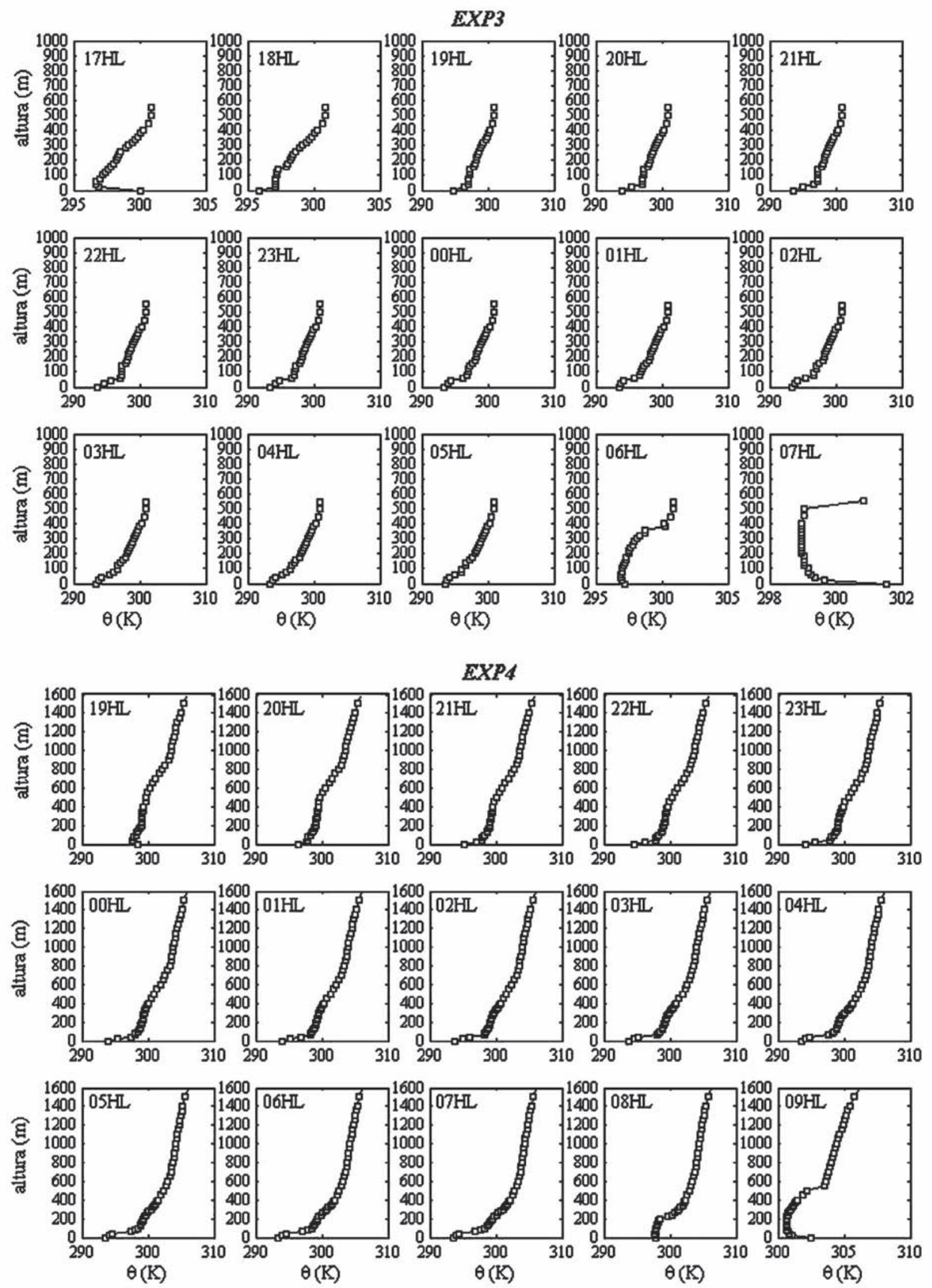

Figura 10 - Perfis horários de temperatura potencial $(\theta)$, obtidos pelas simulações EXP1, EXP2, EXP3 e EXP4, para a Floresta (Continuação). 

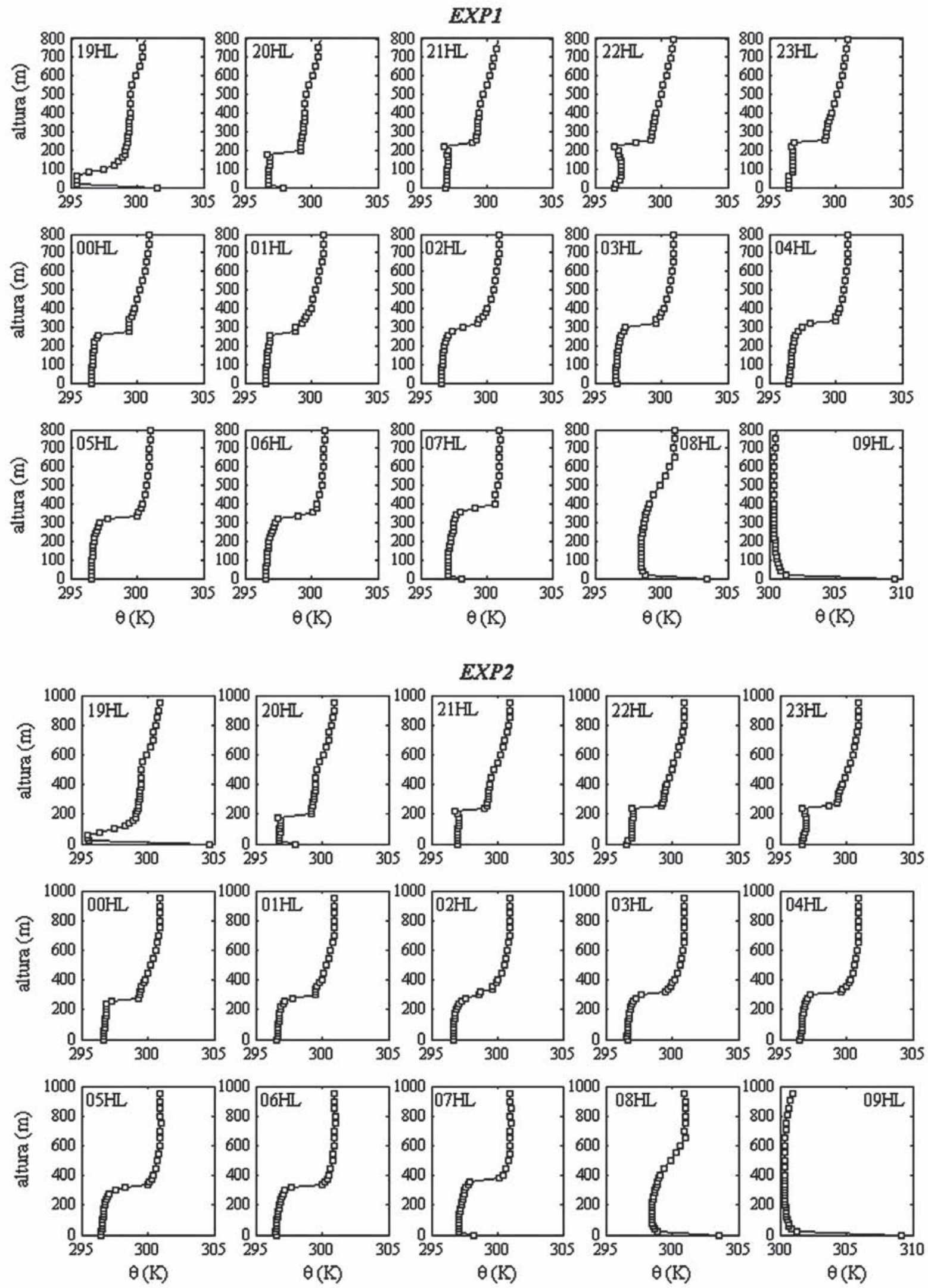

Figura 11 - Perfis horários de temperatura potencial $(\theta)$, obtidos pelas simulações EXP1, EXP2, EXP3 e EXP4, para a FNS. 

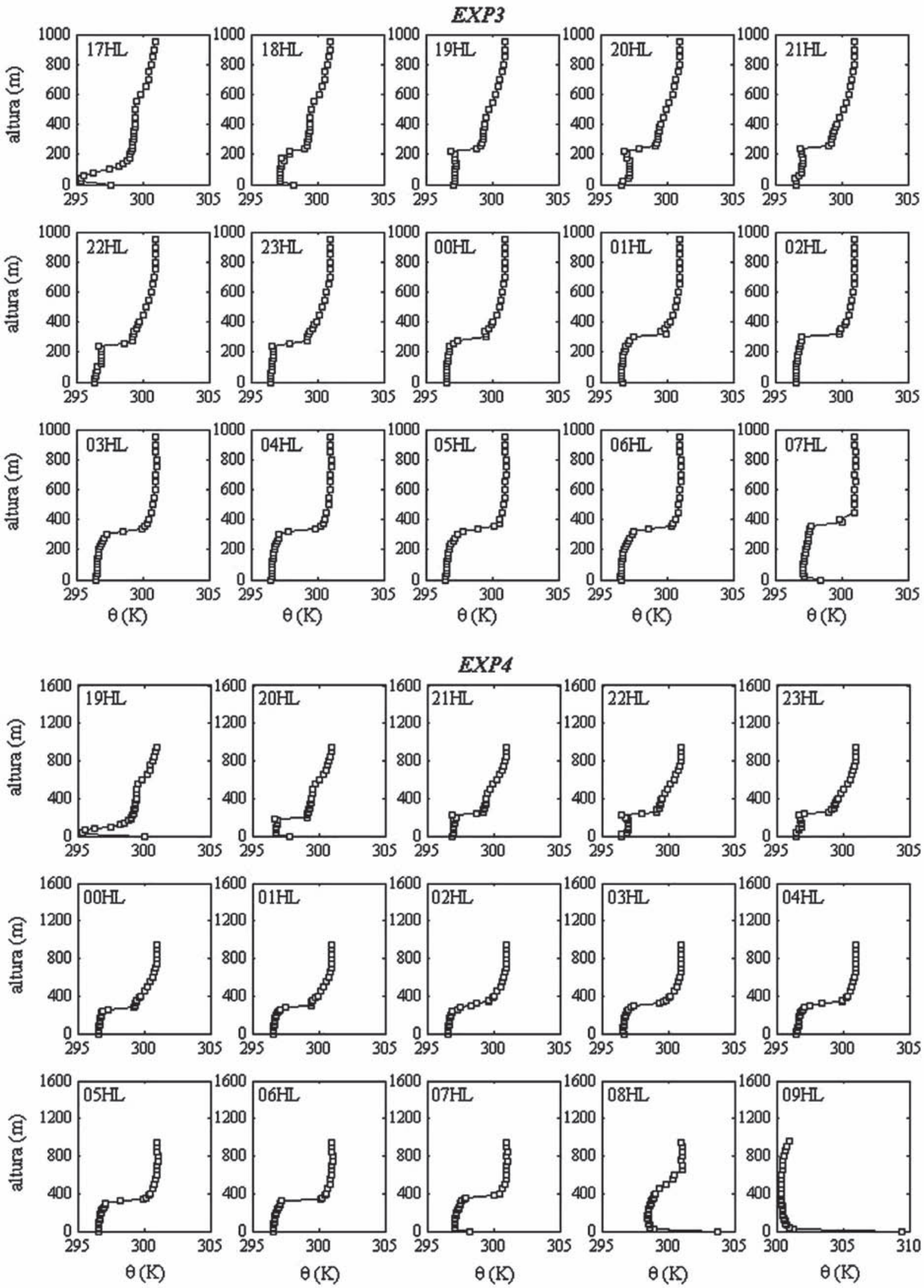

Figura 11 - Perfis horários de temperatura potencial ( $\theta$ ), obtidos pelas simulações EXP1, EXP2, EXP3 e EXP4, para a FNS (Continuação). 
$R M-E X P 4$
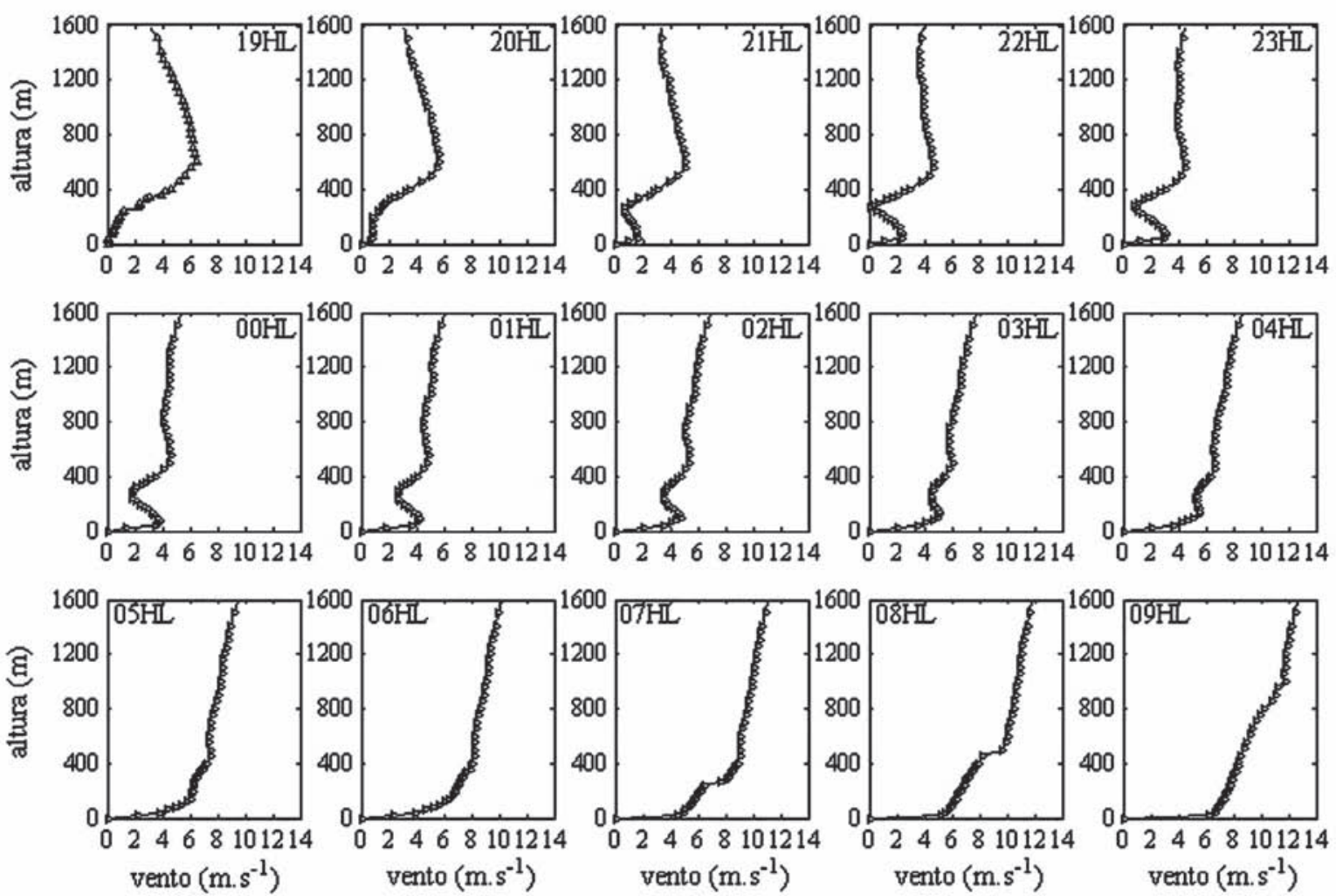

FLORESTA - EXP4
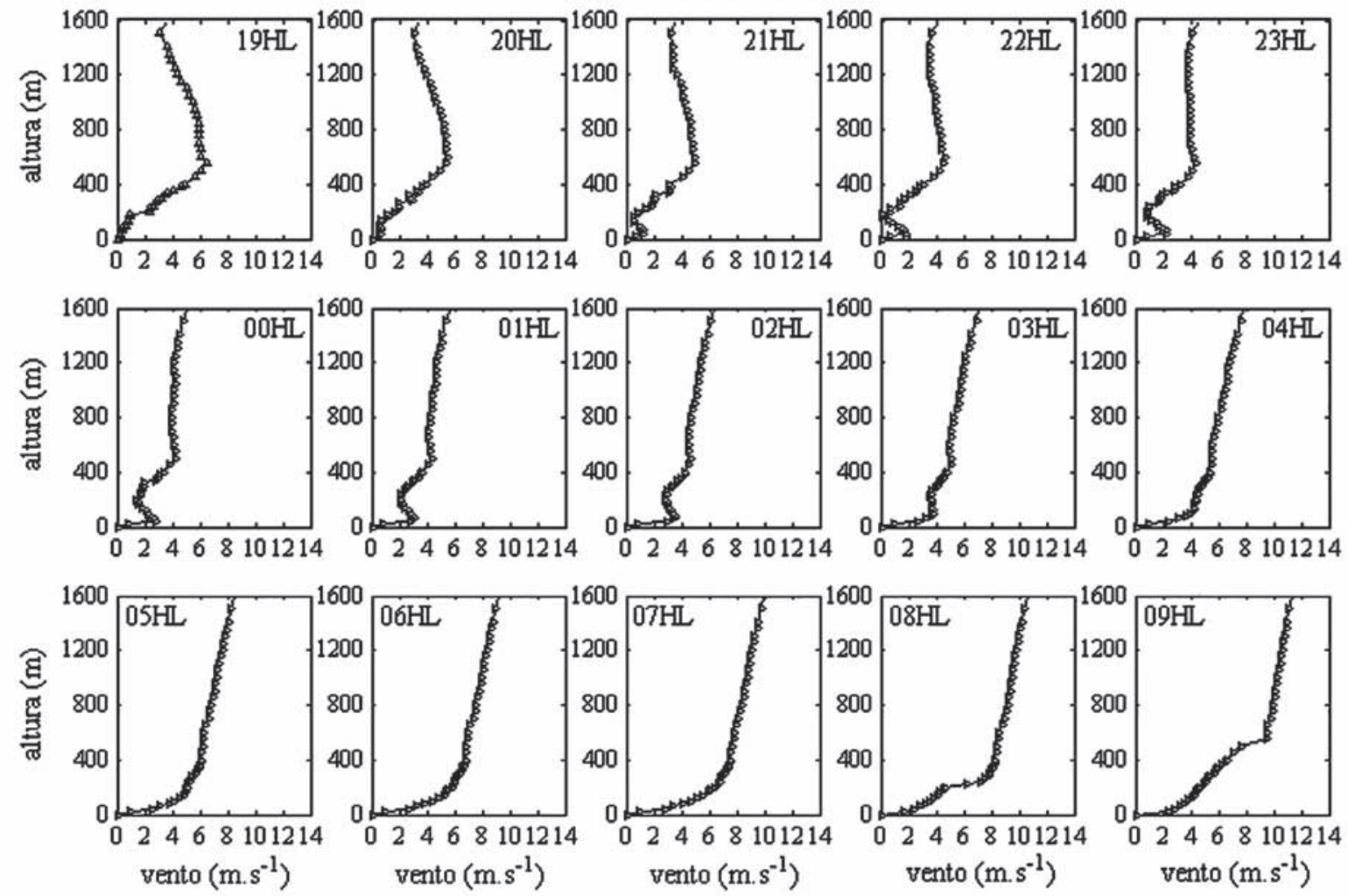

Figura 12 - Perfis de vento estimados a partir da simulação EXP4 para RM, Floresta e FNS. 

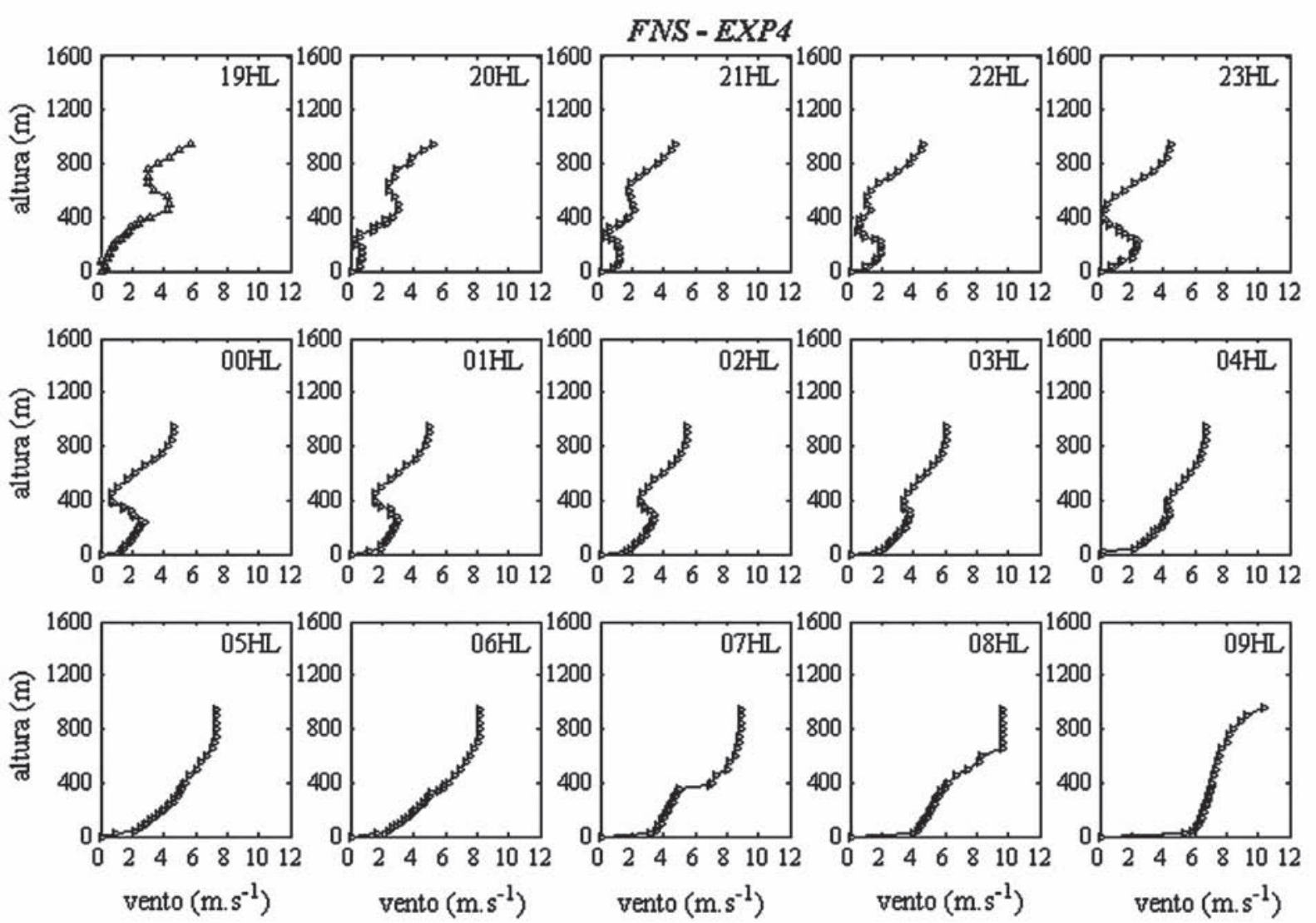

Figura 12 - Perfis de vento estimados a partir da simulação EXP4 para RM, Floresta e FNS (Continuação).

\section{CONCLUSÕES}

As análises destas simulações para a estação úmida mostraram que, em geral, o modelo OSU-CAPS representou razoavelmente a estrutura e o desenvolvimento da CLN, sobre os três sítios utilizados para as simulações. O desenvolvimento da CLN simulado em RM (transição floresta-pastagem) se assemelhou mais àquele simulado para a Floresta, principalmente no período entre $19 \mathrm{hl}$ e 06hl. E no sítio representativo de uma área totalmente desmatada, FNS, as análises indicaram que a CLN tem um desenvolvimento parecido com aquele observado sobre áreas urbanas - onde uma camada de mistura turbulenta rasa é observada próximo à superfície, nas primeiras horas da noite.

A estrutura da CLN apresentou características semelhantes para as simulações que incluíam a cobertura de nuvens (EXP1, EXP2 e EXP3), especialmente em RM e na floresta, com uma camada estável rasa no início da noite, ventos calmos e pouca (ou nenhuma) turbulência, se aprofundando durante a madrugada e ainda mantendo essa tendência de manhã cedo. Tal fato pode estar ligado à limitação do modelo em descrever adequadamente as condições de umidade do solo.

Durante eventos de jato, as simulações mostraram que sobre as áreas desmatadas (RM e FNS), a turbulência mecânica contribuiu mais efetivamente para o aprofundamento da CLN, dominando a organização de sua estrutura. Enquanto na floresta, apesar da ação da mistura turbulenta gerada devido à ocorrência do $\mathrm{JN}$, o resfriamento radiativo no topo da camada desempenha um papel importante sobre a dinâmica da CLN, funcionando como um inibidor desta turbulência e fazendo com que o desenvolvimento da CLN sobre a floresta seja menor.

Perfis de vento estimados pelo modelo mostraram que o aparecimento do jato causa uma perturbação que se reflete nos níveis mais baixos, intensificando os ventos próximos à superfície e, provavelmente, dando origem a movimentos turbulentos que provocam o aparecimento da camada bem misturada observada próximo à superfície, especialmente sobre a FNS, e o desacoplamento da camada superior. 


\section{REFERÊNCIAS BIBLIOGRÁFICAS}

Alvalá, R. C. S.; Gielow, R.; Rocha, H. R. da; Freitas, H. C.; Lopes, J. M.; Manzi, A. O.; Randow, C. von; Dias, M. A. F. S.; Cabral, O. M. R.; Waterloo, M. J. Intradiurnal and seasonal variability of soil temperature, heat flux, soil moisture content, and thermal properties under Forest and pasture in Rondônia. Journal Geophysical Research, v. 107, n. D20, p. X-1 - X-20, 2002.

Coulter, R. L.; Doran, J. C. Spatial and Temporal occurrences of intermittent turbulence during CASES-99. BoundaryLayer Meteor., v. 105, p. 329-349, 2002.

Derbyshire, S. H. Nieuwstadt's stable boundary layer revisited. Quart. J. Roy. Meteorol. Soc., v. 116, p. 127-158, 1990.

Doran, J. C. Characteristics of intermittent turbulent temperature fluxes in stable conditions. Boundary-Layer Meteor., v. 112, p. 241-255, 2004.

Garratt, J. R. The atmospheric boundary layer. Cambridge University Press, Cambridge, 1992, 316 p.

Holtslag, A. A. M.; Duynkerke, G. G. Clear and Cloudy Boundary Layer. Royal Netherlands Academy of Arts and Sciences, Amsterdam, 1998, 371 p.

Holtslag, A. A. M.; Nieuwstadt, F. T. M. Scaling the atmospheric boundary layer. Boundary-Layer Meteor., 36, 201-209, 1986.

Howell, J. F.; Sun, J. Surface-Layer Fluxes in stable conditions. Boundary-Layer Meteor., v. 90, p. 495-520, 1999.

Lenschow, D. H.; Li, X. S.; Zhu, C. J.; Stankov, B.B. The stably stratified boundary layer over the Great Plains. I. Mean and turbulence structure. Boundary-Layer Meteor., 42, 95-121, 1988.

Mahrt, L. Stratified atmospheric boundary layers and breakdown of models. J. Theor. Comput. Fluid Dyn., v. 11, p. 263-280, 1998.

Mahrt, L. Vertical structure and turbulence in the very stable boundary layer. J. Atmos. Sci., v. 42, p. 2333-2349, 1985.

Mahrt, L.; Ek, K. The influence of atmospheric stability on potential evaporation. J. Clim. Appl. Meteor., v. 23, p. 222-234, 1984.
Mahrt, L.; Pan, H. L. A two-layer model of soil hydrology. Boundary-Layer Meteor., v. 90, p. 1-20, 1984.

Malhi, Y. S. The significance of the dual solutions for heat fluxes measured by the temperature fluctuations method in stable conditions. Boundary-Layer Meteor., 74, 389396, 1995.

Murthy, B. S.; Parasnis, S. S.; Ek, M. Interactions of the landsurface with the atmospheric boundary layer: case studies from LASPEX. Current Science, v. 86, n. 8, p. 1128-1134, April 2004.

Nappo, C; Johansson, P. E. Summary report of the lovanger international workshop on turbulence and diffusion in the stable planetary boundary layer. Bull. Amer. Meteor. Soc., v 79, p. 1401-1405. 1998.

Oyha, Y. D.; Neff, E.; Meroney, R. N. Turbulence structure in a stratified boundary layer under stable conditions. Boundary-Layer Meteor., 83, 139-161, 1997.

Pan, H. L.; Mahrt, L. Interaction between soil hydrology and boundary-layer development. Boundary-Layer Meteor., v. 38, p. 185-202, 1987.

Poulos, G. S.; Blumen, W.; Fritts, D. C.; Lundquist, J. K.; Sun, J.; Burns, S. P.; Nappo, C.; Banta, R.; Newsom, R.; Cuxart, J.; Terradellas, E.; Balsley, B.; Jensen, M. CASES-99: A Comprehensive Investigation of the Stable Nocturnal Boundary Layer. Bull. Amer. Meteor. Soc., v. 83, 555-581. 2002 .

Poulos, G. S.; Bossert, J. E. An observational and prognostic numerical investigation of complex terrain dispersion. Journal of Applied Meteor., v. 34, p. 650-669. 1995.

Silva Dias, M.A.F.; Rutlegde, S.; Kabat, P.; Silva Dias, P. L. da; Nobre, C.; Fisch, G.; Dolman, A. J.; Zipser, E.; Garstang, M.; Manzi, A. O.; Fuentes, J. D.; Rocha, H. R.; Marengo, J.; Plana-Fattori, A.; Sá, L. D. A.; Alvalá, R. C. S.; Andreae, M. O.; Artaxo, P.; Gielow, $\mathrm{R}$; Gatti, L. Clouds and rain processes in a biosphereatmosphere interaction context in the Amazon region. Journal Geophysical Research, v. 107, n. D20, p. 8072, 2002.

Smedman, A. S. Observations of a multi-level turbulence structure in a very stable atmospheric boundary layer. Boundary-Layer Meteor., 44, 231-253, 1988. 
Souza, J. R. S. de; Pinheiro, F. M. A.; Araújo, R. L. C. de; Pinheiro Jr., H. S.; Hodnett, M. G. Temperature and moisture profiles in soil beneath forest and pasture areas in eastern Amazonia. In Amazônia Deforestation and Climate, eds. Gash, J. H. C.; Nobre, C. A.; Roberts, J. M.; Victoria, R. L. ,p. 125-137, 1996.

Stull, R. B. An introduction to boundary layer meteorology. Kluwer Academic Publishers, Dordrecht, 1988, 666 pp.

Sun J.; Lenschow, D. H.; Burns, S. P.; Banta, R. M.; Newsom, R. K.; Coulter, R.; Frasier, S.; Ince, T.; Nappo, C.; Balsley, B. B.; Jensen, M.; Mahrt, L.; Miller, D.; Skelly, B. Atmospheric disturbances that generate intermittent turbulence in nocturnal boundary layers. Boundary-Layer Meteor., v. 110, p. 255-279, 2004.
Troen, I.; Mahrt, L. A simple model of the atmospheric boundary layer; sensitivity to surface evaporation. Boundary-Layer Meteor., v. 37, p. 129-148, 1986.

Van Ulden, A. P.; Wieringa, J. Atmospheric boundary-layer research at Cabauw. Boundary-Layer Meteor., 78, 34-69, 1996.

Wright, I. R.; Nobre, C. A.; Tomasella, J.; Rocha, H. R. da; Roberts, J. M.; Vertamatti, E.; Culf, A.; Alvalá, R. C. S.; Hodnett, M. G.; Ubarana, V. N. Towards a GCM surface parameterization of Amazonia. In Amazônia Deforestation and Climate, eds. Gash, J. H. C.; Nobre, C. A.; Roberts, J. M.; Victoria, R. L., 1996, p. 473-504.

Zilitinkevich, S. S.; Mironov, D. A Multi-limit formulation for the equilibrium depth of a stably stratified boundary layer. Boundary-Layer Meteor., 81, 325-351, 1996. 